\title{
Thermophysical Properties of Multifunctional Syntactic Foams Containing Phase Change Microcapsules for Thermal Energy Storage
}

\author{
Francesco Galvagnini *, Andrea Dorigato, Luca Fambri ${ }^{(D)}$, Giulia Fredi ${ }^{(D)}$ and Alessandro Pegoretti $(\mathbb{D}$ \\ Department of Industrial Engineering and INSTM Research Unit, University of Trento, Via Sommarive 9, \\ 38123 Trento, Italy; andrea.dorigato@unitn.it (A.D.); luca.fambri@unitn.it (L.F.); giulia.fredi@unitn.it (G.F.); \\ alessandro.pegoretti@unitn.it (A.P.) \\ * Correspondence: francesco.galvagnini@unitn.it
}

check for updates

Citation: Galvagnini, F.; Dorigato, A.; Fambri, L.; Fredi, G.; Pegoretti, A. Thermophysical Properties of Multifunctional Syntactic Foams Containing Phase Change Microcapsules for Thermal Energy Storage. Polymers 2021, 13, 1790. https://doi.org/10.3390/ polym 13111790

Academic Editors: Giulio Malucelli and Francesco Paolo La Mantia

Received: 11 May 2021

Accepted: 26 May 2021

Published: 28 May 2021

Publisher's Note: MDPI stays neutra with regard to jurisdictional claims in published maps and institutional affiliations.

Copyright: (c) 2021 by the authors Licensee MDPI, Basel, Switzerland. This article is an open access article distributed under the terms and conditions of the Creative Commons Attribution (CC BY) license (https:// creativecommons.org/licenses/by/ $4.0 /)$

\begin{abstract}
Syntactic foams (SFs) combining an epoxy resin and hollow glass microspheres (HGM) feature a unique combination of low density, high mechanical properties, and low thermal conductivity which can be tuned according to specific applications. In this work, the versatility of epoxy/HGM SFs was further expanded by adding a microencapsulated phase change material (PCM) providing thermal energy storage (TES) ability at a phase change temperature of $43^{\circ} \mathrm{C}$. At this aim, fifteen epoxy (HGM/PCM) compositions with a total filler content (HGM + PCM) of up to $40 \mathrm{vol} \%$ were prepared and characterized. The experimental results were fitted with statistical models, which resulted in ternary diagrams that visually represented the properties of the ternary systems and simplified trend identification. Dynamic rheological tests showed that the PCM increased the viscosity of the epoxy resin more than HGM due to the smaller average size (20 $\mu \mathrm{m}$ vs. $60 \mu \mathrm{m})$ and that the systems containing both HGM and PCM showed lower viscosity than those containing only one filler type, due to the higher packing efficiency of bimodal filler distributions. HGM strongly reduced the gravimetric density and the thermal insulation properties. In fact, the sample with $40 \mathrm{vol} \%$ of HGM showed a density of $0.735 \mathrm{~g} / \mathrm{cm}^{3}$ (-35\% than neat epoxy) and a thermal conductivity of $0.12 \mathrm{~W} /(\mathrm{m} \cdot \mathrm{K})(-40 \%$ than neat epoxy). Moreover, the increase in the PCM content increased the specific phase change enthalpy, which was up to $68 \mathrm{~J} / \mathrm{g}$ for the sample with $40 \mathrm{vol} \%$ of PCM, with a consequent improvement in the thermal management ability that was also evidenced by temperature profiling tests in transient heating and cooling regimes. Finally, dynamical mechanical thermal analysis (DMTA) showed that both fillers decreased the storage modulus but generally increased the storage modulus normalized by density $\left(\mathrm{E}^{\prime} / \rho\right)$ up to $2440 \mathrm{MPa} /\left(\mathrm{g} / \mathrm{cm}^{3}\right)$ at $25^{\circ} \mathrm{C}$ with $40 \mathrm{vol} \%$ of HGM ( $+48 \%$ than neat epoxy). These results confirmed that the main asset of these ternary multifunctional syntactic foams is their versatility, as the composition can be tuned to reach the property set that best matches the application requirements in terms of TES ability, thermal insulation, and low density.
\end{abstract}

Keywords: syntactic foams; epoxy; glass microspheres; thermal energy storage; phase change materials; thermal properties

\section{Introduction}

Syntactic foams (SFs) are an innovative class of materials with tailorable properties and are classifiable both as foams and as composites. Their microstructure, obtained by incorporating hollow rigid particles in a matrix, allows a simultaneous reduction in density and an increase in mechanical properties compared to neat polymers. The resulting materials show higher tensile, higher compressive, and higher impact properties per unit weight than traditional foams, but also higher heat insulation performance, dielectric properties, flame resistance, and sound absorption capacity [1]. This unique combination of properties justifies the intensive research and application of syntactic foams in high-end 
and weight-sensitive areas, especially in the fields of transportation, aerospace, and marine fields where syntactic foams are employed to produce thermal insulating panels, stiff lightweight cores in composite sandwich structures, deep-sea pipelines, and other diving equipment [2-7].

Matrices and particles of SFs can be constituted by a broad range of materials. Matrix materials can be polymeric, ceramic, or metallic. Polymeric matrices are the most diffused due to their low density, low cost, and easy processability while metallic and ceramic foams are employed in niche applications requiring exceptional resistance to high temperatures or harsh environment [8]. Hollow particles can be made of various materials, such as glass, boron carbide, silica, and other ceramics; and with different shapes, such as spherical, cubic, cuboid, and cylindric [4]. The most widely studied syntactic foams are those composed of hollow glass microspheres (HGM) and an epoxy matrix [2,9-13]. In fact, although thermoplastic matrices have attracted much interest due to their recyclability and postthermoforming potential $[2,14,15]$, the thermomechanical performance of epoxy resins are still unmatched and thus they are the elective materials for high-end applications in aerospace and automotive fields.

The most interesting feature of polymeric SFs containing HGM is their high versatility. The final density and thermomechanical properties can be tailored by varying the properties of the HGM in terms of size, size distribution, volume fraction, surface chemistry and morphology, and shell thickness. For example, the thermal conductivity of polymeric SFs can either increase or decrease with the HGM concentration depending on the ratio between the volume and the wall thickness of hollow spheres [15]. Such remarkable versatility can be further enhanced by adding a third constituent [3]. The property set of epoxy/HGM SFs has been extended by incorporating microfillers and nanofillers such as milled carbon fibers and carbon nanofibers (CNFs), expanded graphene nanoplatelets (xGnPs), nanoclays, and halloysite nanotubes. For example, the incorporation of milled carbon fibers in an epoxy/HGM SF was proven to enhance the fracture toughness [16] and/or to increase the electrical conductivity of the foams, thus rendering these materials useful for electromagnetic interference (EMI) shielding applications [17]. In this sense, SFs are ideal multifunctional materials since their composition can be finetuned to obtain an interesting combination of mechanical and functional properties, which are useful when load-bearing and weight-saving requirements must be coupled with additional functionalities.

An interesting functional property that could be added to SFs is the thermal energy storage (TES) ability, i.e., the capacity of temporarily storing heat that can be released when and where needed [18-22]. TES technologies are used for thermal management in a wide variety of applications, including transportation and refrigeration chain, buildings, food containers, and smart textiles $[18,23,24]$. The most diffused TES technique in the low-mid temperature range $\left(0-100{ }^{\circ} \mathrm{C}\right)$ harnesses the melting-freezing phase change of organic phase change materials (PCMs) such as paraffin waxes, which store and release a considerable amount of latent heat (up to $250 \mathrm{~J} / \mathrm{g}$ ) at a nearly constant temperature [25-27]. In order to avoid leakage and loss of material above the melting temperature, PCMs are often encapsulated in stable micro-shells and the resulting PCM microcapsules are nontoxic and easy to be incorporated in a polymer matrix [28-30]. Our group has recently investigated the mechanical and TES properties of polymer composites containing such PCM microcapsules and reinforced it with continuous or discontinuous fibers [20,21,31-36], which resulted in multifunctional structural TES composites useful for applications where weight saving, and thermal management are equally important. Similarly, adding PCM microcapsules to polymeric SFs could result in multifunctional materials with tunable thermomechanical properties, to be applied in the automotive and aerospace fields, where low density, thermal management capability, and excellent compressive and flexural properties are often required simultaneously. Despite the potentialities of such epoxy/HGM/PCM ternary systems, no papers can be found in the open scientific literature about syntactic foams containing PCMs to the best of the authors' knowledge. 
This work, therefore, aims to expand the property set of epoxy/HGM syntactic foams via the introduction of a microencapsulated PCM possessing a phase change temperature of $43{ }^{\circ} \mathrm{C}$ to produce a material with an interesting combination of highly specific mechanical properties and thermal management capability. To realize this aim, fifteen epoxy/HGM/PCM composites were prepared with different HGM-to-PCM ratios, with a maximum total filler content of $40 \mathrm{vol} \%$ and the compositions were chosen by using a design of experiment (DOE) approach. The subsequent characterization focused on the rheological, microstructural, and thermal properties of the prepared systems. First, the processability was assessed by evaluating the rheological properties of uncured epoxy/HGM/PCM mixtures as a function of the filler type and concentration. Then, the microstructure and the density of the resulting foams were investigated by utilizing scanning electron microscopy (SEM) and pycnometer density, respectively. The TES properties were studied by differential scanning calorimetry (DSC) and by monitoring the inner temperature of the samples during heating/cooling ramps. Finally, the thermal conductivity was investigated by light flash analysis (LFA), while their viscoelastic properties were evaluated at different temperatures by utilizing dynamic-mechanical thermal analysis (DMTA).

\section{Materials and Methods}

\subsection{Materials}

The epoxy base EC 157 (density $=1.15 \mathrm{~g} / \mathrm{cm}^{3}$, viscosity at $25^{\circ} \mathrm{C}=600-800 \mathrm{mPa} \cdot \mathrm{s}$ ) and the amine hardener W342 (density $=0.95 \mathrm{~g} / \mathrm{cm}^{3}$, viscosity at $25^{\circ} \mathrm{C}=30-70 \mathrm{mPa} \cdot \mathrm{s}$ ) were kindly provided by Elantas Europe Srl. (Collecchio, Italy). The K15 hollow glass microspheres (HGM) were provided by $3 \mathrm{M}$ Italia Srl. (Pioltello, Italy). As reported on the technical datasheet of the producer, they were made of soda-lime-borosilicate glass and had a density of $0.15 \mathrm{~g} / \mathrm{cm}^{3}$, a mean particle size (D50) equal to $60 \mu \mathrm{m}$, a thermal conductivity of $0.055 \mathrm{~W} /(\mathrm{m} \cdot \mathrm{K})$, and a crush strength (90\% survival) of $2.07 \mathrm{MPa}$. The PCM used in this work was an encapsulated paraffin MPCM43D, provided by Microtek laboratories Inc. (Dayton, USA), possessing a density of $0.9 \mathrm{~g} / \mathrm{cm}^{3}$ and a mean size of $17-22 \mu \mathrm{m}$. The melamine-formaldehyde shell, constituting the $15 \mathrm{wt} \%$ of the total mass, guarantees the thermal stability up to $250{ }^{\circ} \mathrm{C}$. The paraffinic core had a melting temperature of $43^{\circ} \mathrm{C}$ and a melting enthalpy of 190-200 J/g. All materials were used as received.

\subsection{Sample Preparation}

Epoxy/PCM/HGM composites were prepared by mixing the epoxy base with PCM and HGM at $100 \mathrm{rpm}$ for one minute through a Dispermat F1 mechanical mixer provided by VMA-Getzmann GmbH (Reichshof, Germany). The mixture was then vacuum-degassed for $5 \mathrm{~min}$. After the addition of the hardener, the resulting compounds were further mixed for $1 \mathrm{~min}$ and vacuum-degassed for $5 \mathrm{~min}$. The mixtures were then casted in silicon molds with different geometry and cured for $24 \mathrm{~h}$ at room temperature and $6 \mathrm{~h}$ at $80^{\circ} \mathrm{C}$. This procedure was adopted to prepare 15 compositions, which are listed in Table 1 . Samples were labeled as EPG-x.y, where $\mathrm{x}$ represents the concentration (vol \%) of PCM and y represents that of HGM. These formulations were selected by using a specific mixture design performed with the software RStudio v.1.4.1103 (RStudio Inc., Boston, MA, USA). The result of such design is represented in Figure 1, which shows the chosen compositions with red dots on a ternary phase diagram. In this paper, the results of the main physical properties of these foams were graphically reported via ternary diagrams similar to that reported in Figure 1. 
Table 1. List of the prepared samples with their nominal composition.

\begin{tabular}{|c|c|c|c|}
\hline Sample & $\begin{array}{c}\text { Epoxy } \\
(\mathrm{vol} \%) /(w t \%)\end{array}$ & $\begin{array}{c}\text { PCM } \\
(\text { Vol } \%) /(w t \%)\end{array}$ & $\begin{array}{c}\text { HGM } \\
(\mathrm{vol} \%) /(w t \%)\end{array}$ \\
\hline EPG-0.0 & $100.0 / 100.0$ & $0.0 / 0.0$ & $0.0 / 0.0$ \\
\hline EPG-0.10 & $90.0 / 98.5$ & $0.0 / 0.0$ & $10.0 / 1.5$ \\
\hline EPG-0.20 & $80.0 / 96.7$ & $0.0 / 0.0$ & $20.0 / 3.3$ \\
\hline EPG-0.30 & $70.0 / 94.5$ & $0.0 / 0.0$ & $30.0 / 5.5$ \\
\hline EPG-0.40 & $60.0 / 91.6$ & $0.0 / 0.0$ & $40.0 / 8.4$ \\
\hline EPG-10.0 & $90.0 / 91.6$ & $10.0 / 8.4$ & $0.0 / 0.0$ \\
\hline EPG-10.10 & $80.0 / 89.3$ & $10.0 / 9.2$ & $10.0 / 1.5$ \\
\hline EPG-10.20 & $70.0 / 86.5$ & $10.0 / 10.1$ & $20.0 / 3.4$ \\
\hline EPG-10.30 & $60.0 / 83.0$ & $10.0 / 11.3$ & $30.0 / 5.7$ \\
\hline EPG-20.0 & $80.0 / 83.0$ & $20.0 / 17.0$ & $0.0 / 0.0$ \\
\hline EPG-20.10 & $70.0 / 79.7$ & $20.0 / 18.7$ & $10.0 / 1.6$ \\
\hline EPG-20.20 & $60.0 / 75.8$ & $20.0 / 20.7$ & $20.0 / 3.5$ \\
\hline EPG-30.0 & $70.0 / 74.0$ & $30.0 / 26.0$ & $0.0 / 0.0$ \\
\hline EPG-30.10 & $60.0 / 69.8$ & $30.0 / 28.6$ & $10.0 / 1.6$ \\
\hline EPG-40.0 & $60.0 / 64.6$ & $40.0 / 35.4$ & $0.0 / 0.0$ \\
\hline
\end{tabular}

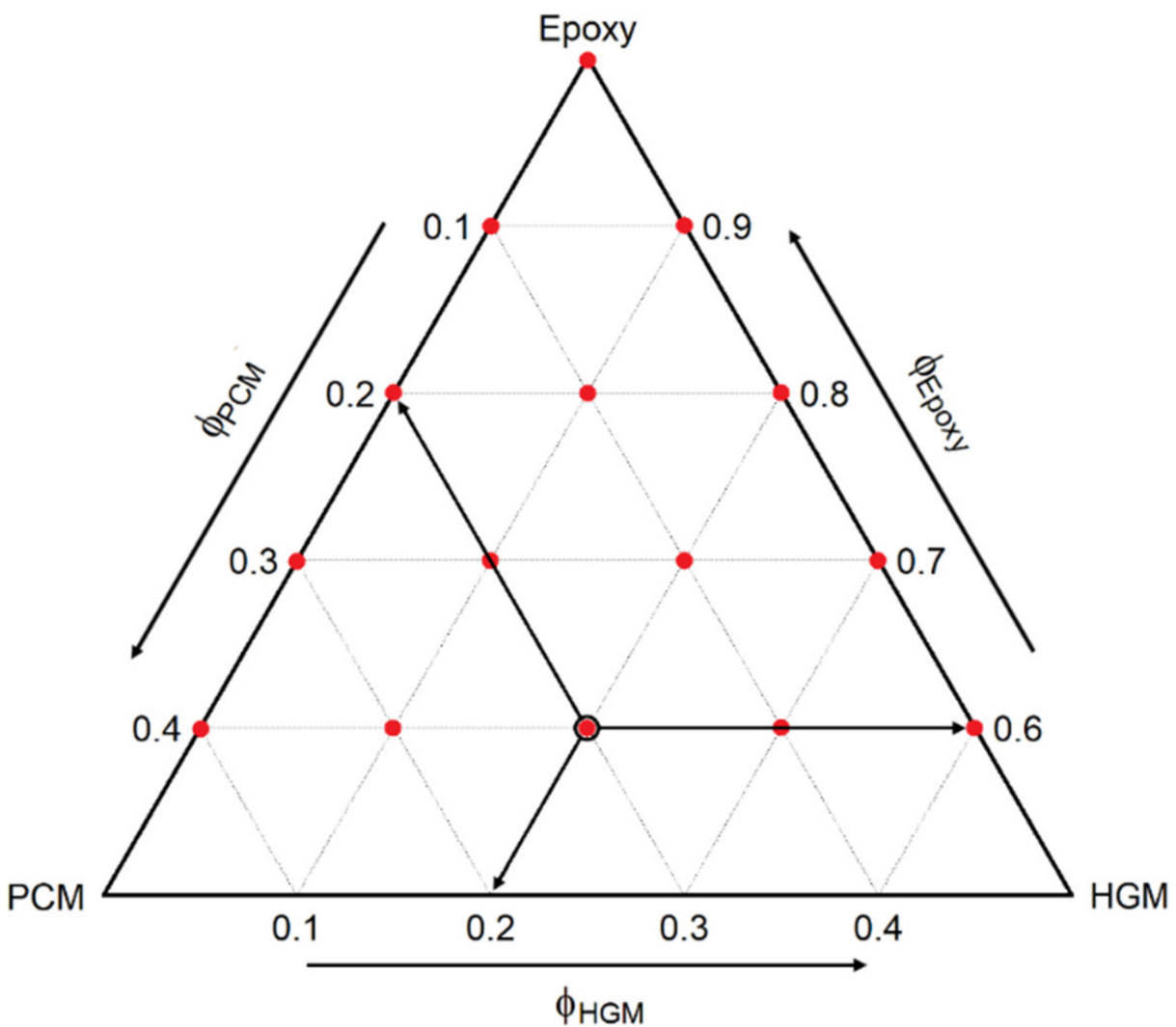

Figure 1. Graphical representation of the prepared compositions (red dots) on the ternary diagram. The black bordered dot refers to the EPG-20.20 foam, possessing a PCM concentration of $20 \mathrm{vol} \%$ and a HGM concentration of $20 \mathrm{vol} \%$.

\subsection{Experimental Techniques}

2.3.1. Rheological and Morphological Properties

The rheological properties play an important role in determining the processing window of thermosetting materials. Hence, a DHR-2 rheometer (TA instrument, New Castle, DE, USA) was used to perform two different analyses on the uncured mixtures by adopting a plate-plate configuration with a gap distance of $1 \mathrm{~mm}$. For both tests, one specimen was tested for each composition. The first test consisted in analyzing the shear 
rate sensitivity between 0.1 and $1 \mathrm{~s}^{-1}$ of 7 compositions, i.e., EPG-0.0, EPG-0.20, EPG-0.40, EPG-10.10, EPG-20.0, EPG-20.20, and EPG-40.0 at a constant temperature of $30^{\circ} \mathrm{C}$. The second test analyzed the dynamic rheological behavior of the mixtures at $70{ }^{\circ} \mathrm{C}, 80^{\circ} \mathrm{C}$, $90{ }^{\circ} \mathrm{C}$, and $110{ }^{\circ} \mathrm{C}$ applying a maximum shear stress of $1000 \mathrm{~Pa}$ at a constant frequency of $1 \mathrm{~Hz}$. This test was performed on 4 compositions, i.e., EPG-0.0, EPG-0.40, EPG-40.0, and EPG-20.20 and allowed determination of the gel time $\left(\mathrm{t}_{\text {gel }}\right)$, which is defined as the time at which the curve of the shear storage modulus $\left(\mathrm{G}^{\prime}\right)$ intersects with that of the shear loss modulus $\left(\mathrm{G}^{\prime \prime}\right)$. These results allowed the determination of the activation energy of crosslinking $\left(\mathrm{E}_{\mathrm{a}}\right)$ via the Arrhenius approach, as is reported in Equation (1):

$$
E_{a}=R\left(\frac{d\left(\ln t_{\text {gel }}\right)}{d(1 / T)}\right)
$$

where $\mathrm{R}$ is the universal gas constant equal to $8.314 \mathrm{~J} /(\mathrm{mol} \cdot \mathrm{K})$ and $\mathrm{T}$ is the testing temperature (in K).

The microstructure of syntactic foams was investigated by analyzing the fracture surface of the prepared (cured) samples with a Zeiss Supra 40 (Carl Zeiss AG, Oberkochen, Germany) scanning electron microscope (SEM) operating at an accelerating voltage of $3.5 \mathrm{kV}$ after Pt-Pd sputtering.

Density measurements were performed for all the compositions on small samples of approximately $3 \mathrm{~g}$ with a Micromeritics AccuPyc 1330TC (Micromeritics Instrument Corp., Norcross, GA, USA) helium pycnometer operating at $23.0^{\circ} \mathrm{C}$ and equipped with a testing chamber of $1 \mathrm{~cm}^{3}$. One specimen was tested 30 times for each composition and the average of the 30 measurements was presented as the result.

\subsubsection{Thermal Properties}

Differential scanning calorimetry (DSC) was performed with a Mettler DSC30 instrument (Mettler Toledo LLC, Columbus, OH, USA) on all the prepared foams and on the neat PCM. Specimens of approximately $40 \mathrm{mg}$ were sealed in $160-\mu \mathrm{l}$ aluminum crucibles and subjected to a cycle of three scans (heating, cooling, and heating) between $10^{\circ} \mathrm{C}$ and $160{ }^{\circ} \mathrm{C}$ at a heating/cooling rate of $+10{ }^{\circ} \mathrm{C} / \mathrm{min}$ under a nitrogen flow of $100 \mathrm{~mL} / \mathrm{min}$. One specimen was tested per composition. These tests allowed the determination of the melting and crystallization temperature of the $\mathrm{PCM}\left(\mathrm{T}_{\mathrm{m} 1}, \mathrm{~T}_{\mathrm{c}}\right.$, and $\left.\mathrm{T}_{\mathrm{m} 2}\right)$, the specific melting and crystallization enthalpy of the $\operatorname{PCM}\left(\Delta \mathrm{H}_{\mathrm{m} 1}, \Delta \mathrm{H}_{\mathrm{c}}\right.$, and $\left.\Delta \mathrm{H}_{\mathrm{m} 2}\right)$, and the glass transition temperature of the epoxy matrix $\left(\mathrm{T}_{\mathrm{g}}\right)$. Furthermore, the specific heat $\left(\mathrm{c}_{\mathrm{p} 30}\right)$ at $30^{\circ} \mathrm{C}$ was calculated from the DSC thermograms in the first heating scan by dividing the specific heat flow by the heating rate at $30^{\circ} \mathrm{C}$. Although this method does not comply with ASTM E-1269 standard, the obtained $c_{p}$ values were used to determine, at least from a qualitative point of view, the thermal conductivity of the prepared foams according to Equation (2).

The TES capability of the prepared samples was also investigated on a larger scale by testing the cylindrical specimens (diameter $20 \mathrm{~mm}$, height $35 \mathrm{~mm}$ ) of some selected compositions, i.e., EPG-0.0, EPG-0.20, EPG-0.40, EPG-10.10, EPG-20.0, EPG-20.20, and EPG-40.0. A blind hole with a diameter of $2 \mathrm{~mm}$ and a depth of $20 \mathrm{~mm}$ was machined on one base of the specimens to allow for the insertion of a type-K thermocouple connected to a recording system. These specimens were subjected to two different thermal ramps, i.e., from $25^{\circ} \mathrm{C}$ to $60^{\circ} \mathrm{C}$ and from 60 to $25^{\circ} \mathrm{C}$ as they were placed in an oven $\left(60{ }^{\circ} \mathrm{C}\right)$ for $40 \mathrm{~min}$ and then pulled out and left for cooling at $25^{\circ} \mathrm{C}$ while their inner temperature was recorded at 1 point per second during the thermal transients. In this way, it was possible to obtain the time required by each sample to reach the temperature of $55^{\circ} \mathrm{C}\left(\mathrm{t}_{26-55}\right)$ in the heating ramp and the temperature of $26^{\circ} \mathrm{C}\left(\mathrm{t}_{55-26}\right)$ in the cooling ramp.

The thermal diffusivity and conductivity of the prepared foams were determined by using a light flash analyzer LFA 467 (Netzsch Holding, Selb, Germany). Tests were performed at $30^{\circ} \mathrm{C}$ on seven compositions, i.e., EPG-0.0, EPG-0.20, EPG-0.40, EPG-10.10, EPG-20.0, EPG-20.20, and EPG-40.0. One square specimen $\left(12.7 \times 12.7 \times 4 \mathrm{~mm}^{3}\right)$ for 
each composition was cut from a cast plate and coated with graphitic spray and three pulses were performed for each sample. These tests allowed the direct measurement of the thermal diffusivity $(\alpha)$. Then, the thermal conductivity at $30^{\circ} \mathrm{C}\left(\lambda_{30^{\circ}} \mathrm{C}\right)$ was calculated by using Equation (2):

$$
\lambda_{30}{ }^{\circ} \mathrm{C}=\alpha \cdot \rho \cdot \mathrm{c}_{\mathrm{p} 30}
$$

where $\rho$ is the pycnometer density $\left(\right.$ at $23.0^{\circ} \mathrm{C}$ ) and $\mathrm{c}_{\mathrm{p} 30}$ is the specific heat calculated from the first scan of the DSC at $30^{\circ} \mathrm{C}$.

\subsubsection{Dynamic-Mechanical Properties}

Dynamic mechanical thermal analysis (DMTA) was performed with a TA Q800DMA analyzer (TA Instruments, New Castle, DE, USA) on eight compositions, i.e., EPG-0.0, EPG0.10, EPG-0.30, EPG-0.40, EPG-10.30, EPG-30.0, EPG-30.10, and EPG-40.0. One rectangular specimen $\left(10 \times 4 \times 40 \mathrm{~mm}^{3}\right)$ for each composition was tested in the single cantilever bending mode by setting a distance of $17.5 \mathrm{~mm}$ between grips. Tests were conducted from $0{ }^{\circ} \mathrm{C}$ to $150{ }^{\circ} \mathrm{C}$ at $3{ }^{\circ} \mathrm{C} / \mathrm{min}$, while the strain amplitude and frequency were set to $0.05 \%$ and $1 \mathrm{~Hz}$, respectively. These tests permitted the obtaining of the trends of the storage modulus $\left(\mathrm{E}^{\prime}\right)$ and loss tangent $(\tan \delta)$ as a function of temperature. The values of the storage modulus $\mathrm{E}^{\prime}$ at $25^{\circ} \mathrm{C}, 60{ }^{\circ} \mathrm{C}$, and $130{ }^{\circ} \mathrm{C}$ were used to elaborate three different ternary plots to better evaluate the $\mathrm{E}^{\prime}$ trend. These values of $\mathrm{E}^{\prime}$ were divided by the pycnometer density measured at $23{ }^{\circ} \mathrm{C}$ to obtain the specific storage modulus $\left(E^{\prime} / \rho\right)$. Since there was no equipment capable of measuring the density of materials at temperatures other than $23^{\circ} \mathrm{C}$ in our laboratory, the pycnometer density at $23{ }^{\circ} \mathrm{C}$ was used to normalize the values of $\mathrm{E}^{\prime}$ acquired at higher temperature.

\subsubsection{Design of Experiment (DOE) and Statistical Analysis of the Experimental Data}

The analysis of the properties of a ternary system can be a very long process, due to the broad variety of possible compositions. Hence, a statistical approach was implemented in this paper to define the mixture design and represent the obtained results by using the RStudio v.1.4.1103 software (RStudio, Inc., Boston, USA). The "mixexp" package was used for the mixture model part and resulted in 15 selected compositions (see Figure 1 and Table 1). Then, the experimental results were fitted with the " $1 \mathrm{~m}$ " function by a quadratic linear model called "Scheffé quadratic model" [36] as reported in Equation (3)

$$
y=\sum_{i=1}^{q} \beta_{i} x_{i}+\sum_{i=1}^{q-1} \sum_{j=i+1}^{q} \beta_{i j} x_{i} x_{j}+\epsilon
$$

where $y$ is the response variable, $x_{i}$ and $x_{j}$ denotes the binary mixture compositions, $\beta_{i}$ represents the expected response at the vertex, and $\beta_{\mathrm{ij}}$ are the coefficients indicating the amount of quadratic curvature along the edge of the simplex region [37]. After a first fit, the most significant components of the model $\left(\mathrm{x}_{\mathrm{i}}, \mathrm{x}_{\mathrm{j}}\right)$ were evaluated through the analysis of variance (ANOVA), while all non-significant components and combinations of components were removed from the model and a new fit with the corrected model was performed. This procedure was repeated until only the statistically significant combinations of components remained. At this juncture, the model can be considered statistically correct and used to represent the analyzed data. The function "ModelPlot" was used to plot the ternary models and the resulting $R^{2}$ adj of the fitting model was noted on each plot. This method has been adopted to elaborate all the ternary plots reported in this work.

\section{Results}

\subsection{Rheological and Morphological Properties}

The processability window of a thermosetting system can be effectively investigated by measuring its rheological properties in the uncured state following the mixing step. The results of the dynamic rheological tests performed on the prepared mixtures are illustrated in Figure $2 \mathrm{a}, \mathrm{b}$. The viscosity $(\eta)$ decreases by increasing the applied shear rate $(\dot{\gamma})$ for all the 
investigated compositions (Figure 2a). This behavior was expected since the system is still in the liquid state and the very beginning of the curing process is not yet detectable [38]. Conversely, the introduction of solid particles (PCM and / or HGM) determines a significant increase in $\eta$, which is especially evident at higher values of $\dot{\gamma}$ and this aspect could reduce the workability of the system. For example, the value of $\eta$ at $0.2 \mathrm{~s}^{-1}$ for the sample EPG10.10 is $5.5 \mathrm{~Pa} \cdot \mathrm{s}(+77 \%$ compared to EPG-0.0 foam) and for the sample EPG-40.0 is $21.8 \mathrm{~Pa} \cdot \mathrm{s}$ (+603\% compared to EPG-0.0 sample).
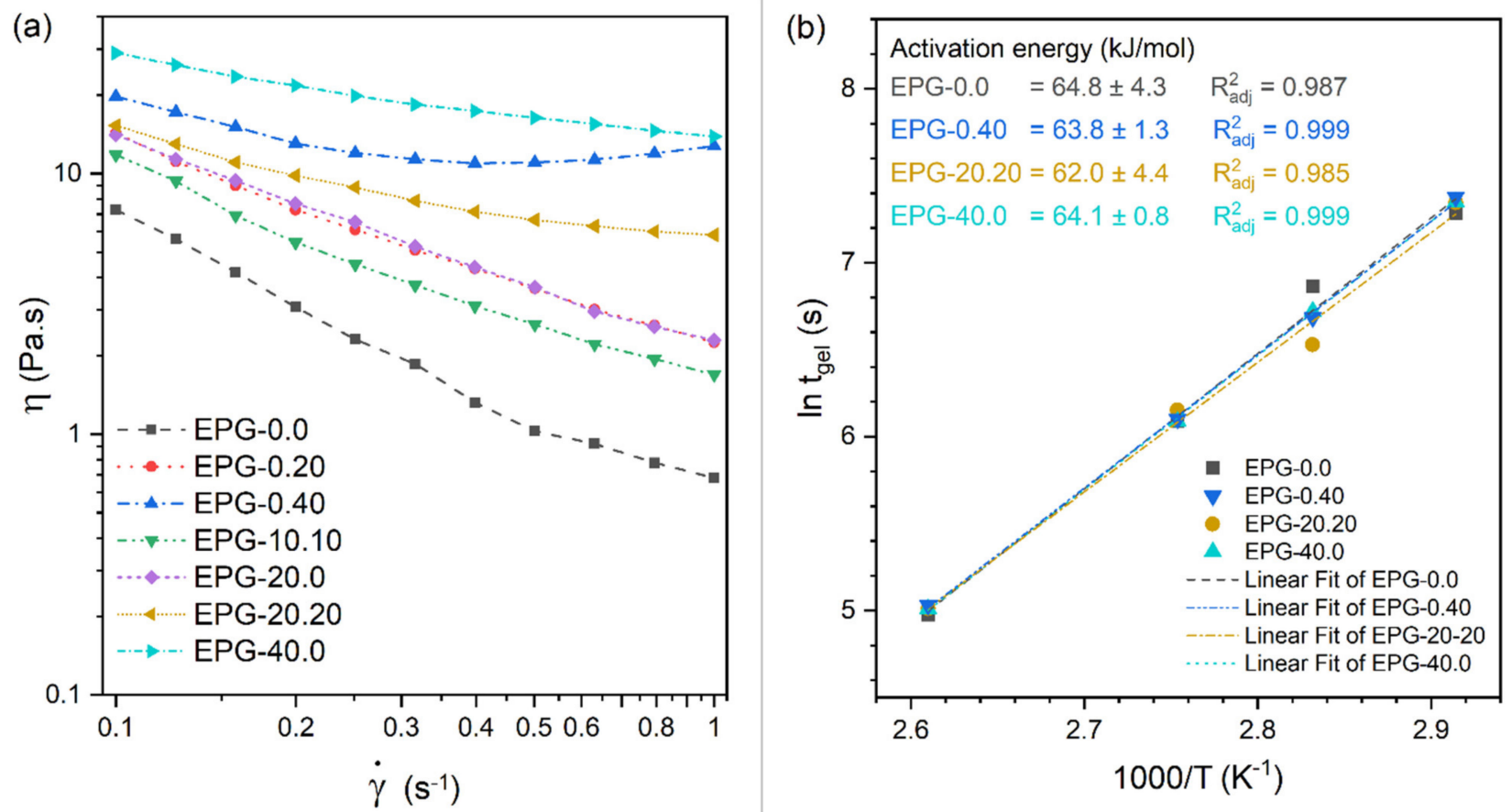

Figure 2. Results of dynamic rheological tests on uncured resins. (a) Viscosity $(\eta)$ as a function of the shear rate $(\dot{\gamma})$ of some selected compositions $\left(\mathrm{T}=30^{\circ} \mathrm{C}\right)$. (b) Gel time $\left(\mathrm{t}_{\text {gel }}\right)$ as a function of the curing temperature $(1000 / \mathrm{T})$ of some selected compositions. Experimental data (symbols) were fitted with Equation (1) (dashed lines) to obtain the activation energy of the crosslinking process.

The effect of the type and concentration of solid particles on the viscosity of the liquid resin deserves a deeper insight. When considering samples containing only one particle type (PCM or HGM), the particle type has no effects on viscosity up to a content of $20 \mathrm{vol} \%$ and, in fact, the samples EPG-0.20 and EPG-20.0 have very similar values of viscosity over the whole range of shear rate. On the other hand, the particle type does influence the rheological properties at higher filler concentrations, with the PCM increasing the viscosity more than HGM, especially at low shear rates. For example, the viscosity of the sample EPG- 0.40 containing $40 \mathrm{vol} \%$ of PCM has a viscosity of $13.1 \mathrm{~Pa} \cdot \mathrm{s}$ at $0.2 \mathrm{~s}^{-1}$, which is approximately $66 \%$ higher than that of the sample EPG- 40.0 containing $40 \mathrm{vol} \%$ of HGM. This is related to the average particle size. Since PCM has a smaller particle size than HGM (approximately $20 \mu \mathrm{m}$ vs. $60 \mu \mathrm{m}$ ), the matrix-filler contact area is larger and therefore the tendency to form a percolative network increases, thus leading a more severe increase in viscosity [39].

Considering the samples containing both particle types, EPG-10.10 and EPG-20.20, they have a lower viscosity than those containing a single particle type at the same filler concentration. This is, again, due to the different particle size which influences the maximum theoretical particle volume fraction reached with random close packing configuration and, in turn, the viscosity. The maximum theoretical volume fraction for close-packed spherical particles is $64 \mathrm{vol} \%$ when the size distribution is unimodal. However, this value can increase for bimodal or multimodal distributions because fine particles can settle within the interstices of coarser particles [38]. This phenomenon, widely described in the literature, 
helps to explain the lower viscosity of samples containing both PCM and HGM. In fact, the higher the maximum theoretical packing density, the lower the viscosity at a given concentration [39-43].

Rheological tests carried out on the uncured mixtures at constant shear rate and at four different temperatures (from $70{ }^{\circ} \mathrm{C}$ to $110^{\circ} \mathrm{C}$ ) provides information on the gel time $\left(t_{\text {gel }}\right)$ and allows for the calculation of the activation energy of the crosslinking process for the different compositions (Equation (1)). The results of these tests are illustrated in Figure 2b, which reports the natural logarithm of $t_{\text {gel }}$ as a function of $1000 / T$ and the values of activation energy of crosslinking determined from the slope of the linear regressions. Interestingly, the activation energy is not significantly different in the four analyzed compositions, as is found in previous studies on epoxy/HGM systems [44]. This suggests that the inclusion of PCM and/or HGM does not influence the crosslinking mechanism of the epoxy resin and does not narrow the processing window.

The microstructure of the cured samples was analyzed by utilizing SEM and Figure 3a-d shows the SEM micrographs of the fracture surface of some selected compositions (EPG-0.0, EPG-0.40, EPG-40.0, and EPG-20.20). All samples exhibit a brittle fracture, as evidenced by the flat fracture surface. HGM (Figure 3b) are homogeneously dispersed within the epoxy matrix and with a good interfacial adhesion and this is evidenced by the absence of gaps between the outer shell surface and the matrix. HGM show a brittle behavior themselves and this is observable from the cracks on some shell fragments (as shown by the arrow on Figure 3b). Moreover, the fact that most HGM are empty and with a smooth inner side suggests that the breakage occurred during the fracture process and not during the mixing phase, which confirms that the adopted processing parameters are mild enough to preserve their integrity.

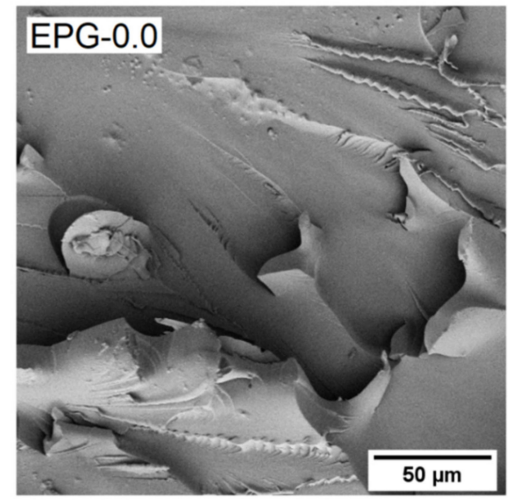

(a)

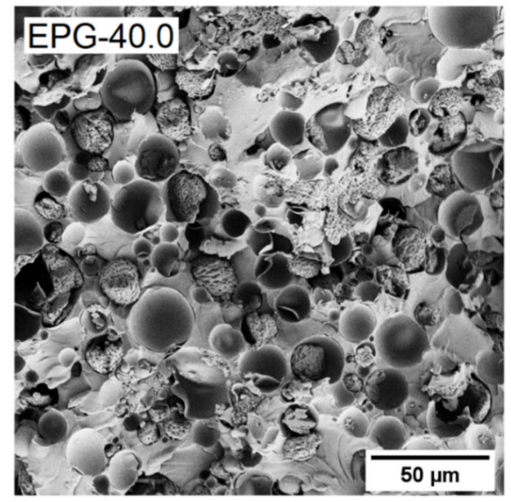

(c)

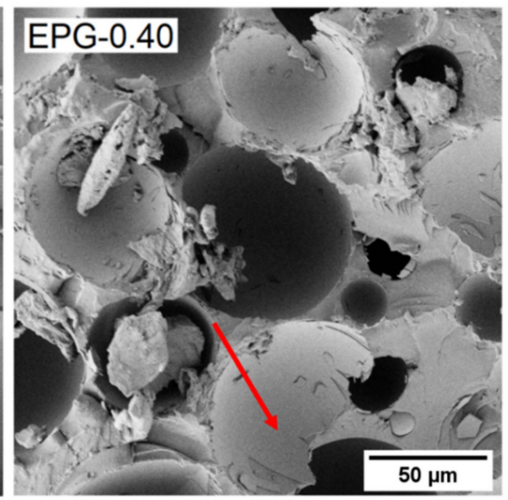

(b)

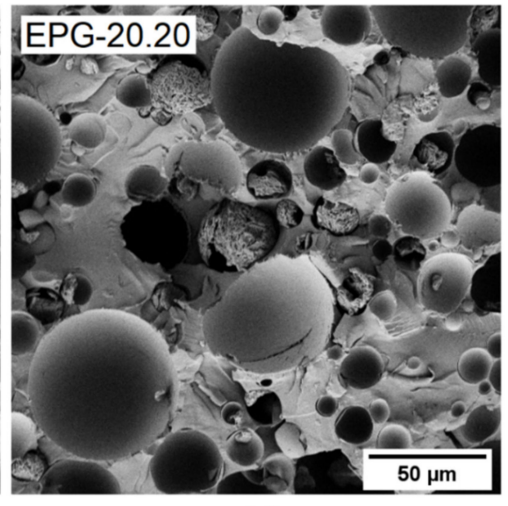

(d)

Figure 3. SEM micrographs of the fracture surface of some selected compositions: (a) EPG-0.0, (b) EPG-0.40, (c) EPG-40.0, and (d) EPG-20.20 (the arrow indicates some cracks on the HGM shell fragments). 
Figure $3 \mathrm{c}$ shows the microstructure of the sample EPG-40.0, containing $40 \mathrm{vol} \%$ of PCM. The PCM is constituted by core-shell spherical microcapsules with an average diameter of approximately $20 \mu \mathrm{m}$ which is observed in previous literature [38] and in good agreement with the producer's datasheet. The adhesion between the outer PCM shell and the epoxy matrix is not optimal and this is better observed on higher-magnification micrographs (not reported for brevity). However, the fact that most PCM microcapsules are broken suggests that the fracture propagates across the microcapsules and not at the interface with the epoxy matrix $[45,46]$. In any case, the low interfacial adhesion could represent a drawback of the proposed system and will be addressed in future research. Moreover, most PCM capsules still show their rough and irregular paraffinic core, while the core of the smooth empty capsules has probably remained on the other side of the fracture surface. This suggests that the integrity of the PCM is preserved during processing, thereby excluding any possibility for paraffinic core to leak out of the composite during service. A comparison between Figure 3b,c evidences the size difference between PCM and HGM, and this is confirmed from the micrograph of the sample EPG-20.20 (Figure 3d), which also evidences the relative distribution of the fillers. In fact, the smaller PCM capsules are located in the interstices of the bigger HGM in good agreement with the results of the rheological measurements (see Figure 2a).

One of the most important and interesting aspects of syntactic foams is their capability to reach a very low density while keeping high stiffness and strength. Therefore, the density of the prepared samples was measured via helium pycnometry and the obtained values were fitted with a linear statistical model (as explained in Section 2.3.4) to obtain the ternary diagram reported in Figure 4 . The bulk density of neat and cured epoxy is $1.137 \mathrm{~g} / \mathrm{cm}^{3}$. Since the bulk density of HGM $\left(0.150 \mathrm{~g} / \mathrm{cm}^{3}\right)$ is lower than that of PCM $\left(0.955 \mathrm{~g} / \mathrm{cm}^{3}\right)$, it is unsurprising that the density decreases more due to HGM than to PCM. For instance, the density of the sample EPG-20.20 is $0.872 \mathrm{~g} / \mathrm{cm}^{3}$ ( $-23 \%$ than neat epoxy), while that of EPG-0.40, containing only HGM but having the same total filler amount, is $0.735 \mathrm{~g} / \mathrm{cm}^{3}$ ( $-35 \%$ than neat epoxy). The experimental values of density, thanks to the application of the linear model, can also be applied to evaluate the density for the intermediate compositions. The results of the linear model, obtained with a high $R^{2}$ adj value (0.988), are in good agreement with the mixture rule, which suggests that most of the HGM and PCM capsules survived the processing step.

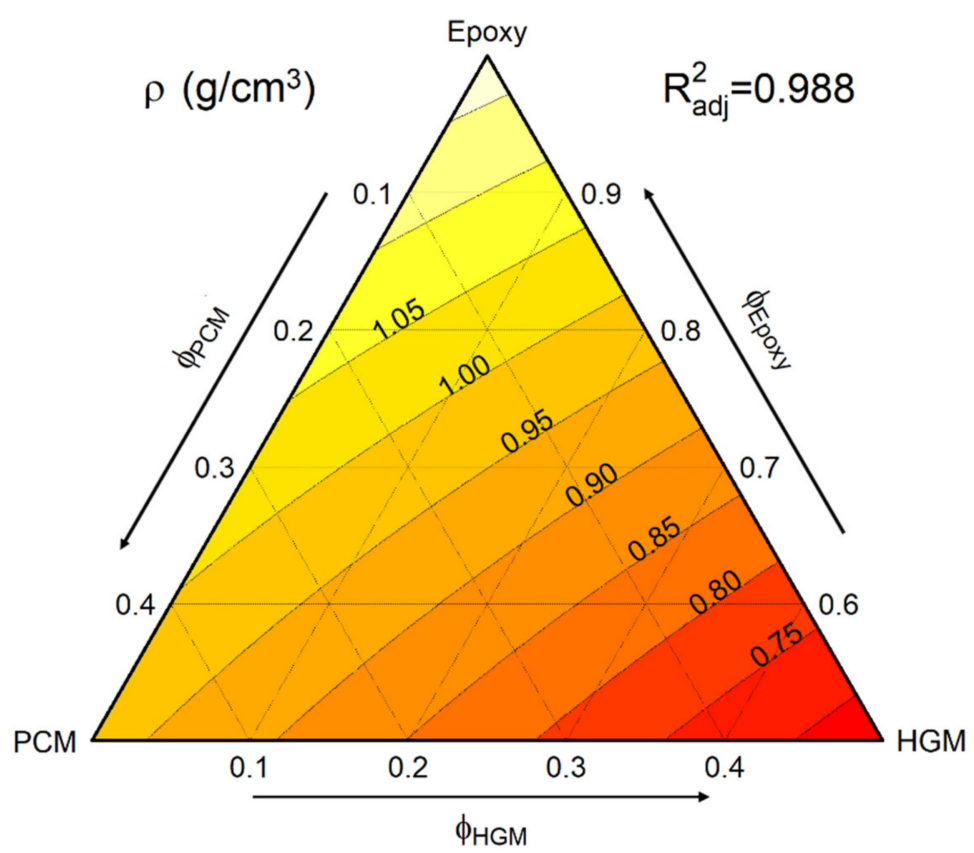

Figure 4. Fit-model of the pycnometer density of the prepared syntactic foams. 


\subsection{Thermal Properties}

The addition of PCM to epoxy/HGM syntactic foams enriches them with TES properties, i.e., the capability of absorbing and releasing heat in a specific temperature range. Among the techniques to measure TES properties, DSC is one of the most widely used because it requires a small amount of sample and allows the measuring of latent heat stored and released by evaluating the total phase change enthalpy. In this work, DSC was employed to measure not only the melting/crystallization enthalpy of the PCM $\left(\Delta \mathrm{H}_{\mathrm{m} 1}\right.$, $\left.\Delta \mathrm{H}_{\mathrm{c}}\right)$ and the corresponding phase change temperatures $\left(\mathrm{T}_{\mathrm{m} 1}, \mathrm{~T}_{\mathrm{c}}\right)$ but also the glass transition temperature of the epoxy matrix during the first heating scan $\left(\mathrm{T}_{\mathrm{g} 1}\right)$ and the specific heat of the foams at $30^{\circ} \mathrm{C}\left(\mathrm{c}_{\mathrm{p} 30}\right)$. All these results were collected by performing heating/cooling/heating DSC scans, but only the data of the first heating scan are presented in Figure $5 \mathrm{a}, \mathrm{b}$ while Table 2 also shows the results of the cooling scan.

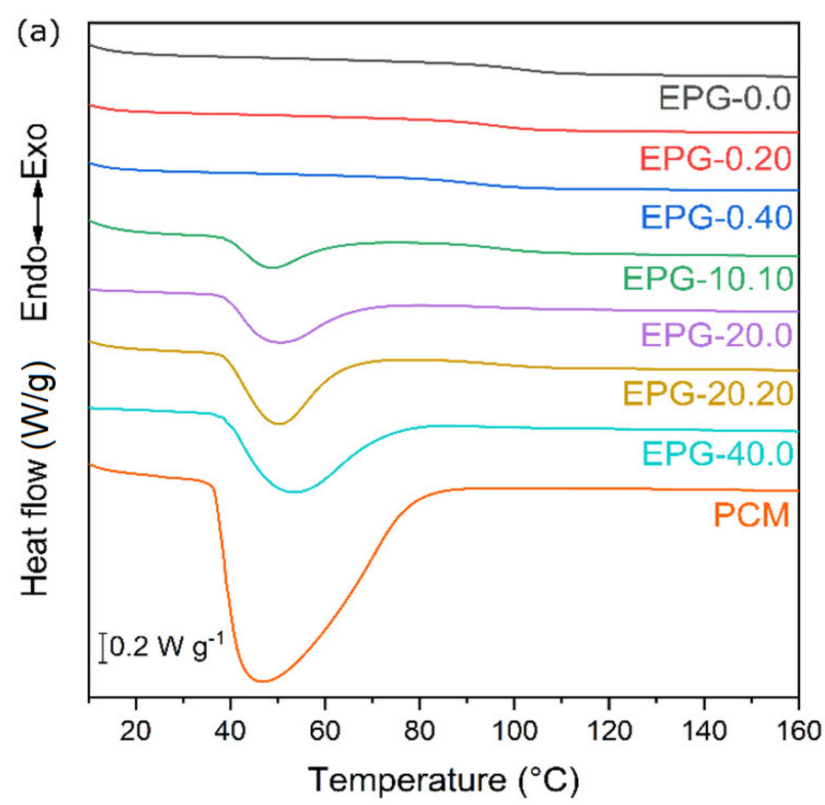

(b)

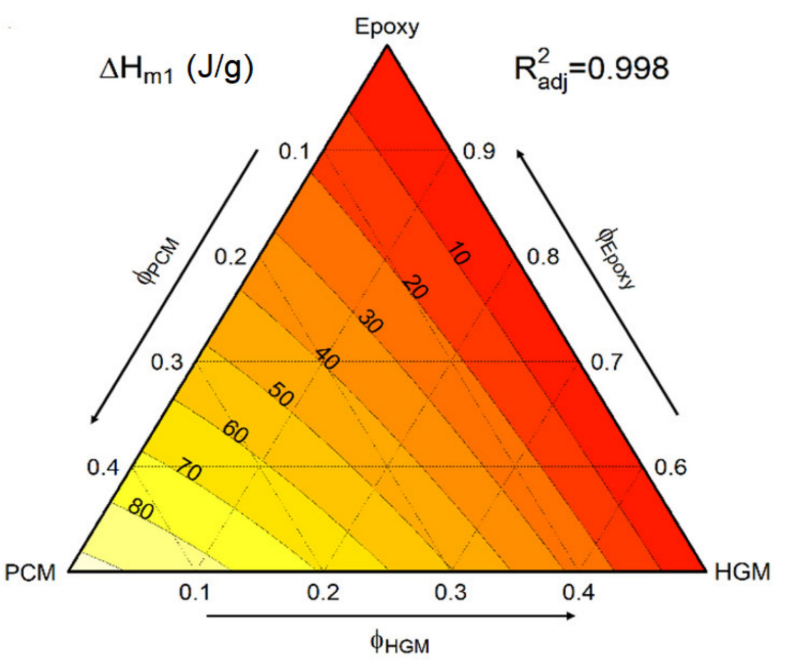

Figure 5. (a) DSC thermograms of the neat PCM and of the prepared foams (first heating scan); (b) fit-model of the melting enthalpy values (first heating scan) of the prepared foams.

Figure 5a shows the DSC thermograms of neat PCM and of some selected compositions. Neat PCM shows a prominent endothermic peak between $35^{\circ} \mathrm{C}$ and $60^{\circ} \mathrm{C}$, associated to the melting of the paraffinic core, as is already observed in previous works on the same PCM $[33,47]$. This signal is also observable in all PCM-containing samples in the same temperature range. The related peak temperatures and enthalpy values are reported in Table 2 as $\mathrm{T}_{\mathrm{m} 1}$ and $\Delta \mathrm{H}_{\mathrm{m} 1}$, respectively. The values of $\mathrm{T}_{\mathrm{m} 1}$ slightly increases with PCM concentration, which is probably due to an increased thermal inertia, as is already observed in previous works on the same PCM [38]. In any case, the temperature interval in which the heat is exchanged is very similar for all the investigated samples. It can be noticed that $T_{c}$ is generally lower than $T_{m 1}$. This phenomenon, probably due to thermal inertia, is already observable for neat microcapsules for which $\mathrm{T}_{\mathrm{m} 1}$ and $\mathrm{T}_{\mathrm{C}}$ are $45.9^{\circ} \mathrm{C}$ and $27.9^{\circ} \mathrm{C}$, respectively, and is even more evident on all the other samples for which the thermal conductivity is lower. In fact, while $\mathrm{T}_{\mathrm{m} 1}$ varies between $47{ }^{\circ} \mathrm{C}$ and $53{ }^{\circ} \mathrm{C}, \mathrm{T}_{\mathrm{c}}$ is spans between $19^{\circ} \mathrm{C}$ and $24^{\circ} \mathrm{C}$. 
Table 2. Main results of DSC tests on the prepared foams (first and second scans).

\begin{tabular}{lcccccc}
\hline Sample & $\begin{array}{c}\mathbf{c}_{\mathbf{p} 30} \\
\mathbf{J} \cdot \mathbf{g}^{-\mathbf{1}} \mathbf{K}^{-\mathbf{1}}\end{array}$ & $\begin{array}{c}\mathbf{T}_{\mathbf{m} \mathbf{1}} \\
{ }^{\circ} \mathbf{C}\end{array}$ & $\begin{array}{c}\Delta \mathbf{H}_{\mathbf{m} 1} \\
\mathbf{J} \cdot \mathbf{g}^{-\mathbf{1}}\end{array}$ & $\begin{array}{c}\mathbf{T}_{\mathbf{g 1}} \\
{ }^{\circ} \mathbf{C}\end{array}$ & $\begin{array}{c}\mathbf{T}_{\mathbf{c}} \\
{ }^{\circ} \mathbf{C}\end{array}$ & $\begin{array}{c}\Delta \mathbf{H}_{\mathbf{c}} \\
\mathbf{J} \cdot \mathbf{g}^{-\mathbf{1}}\end{array}$ \\
\hline EPG-0.0 & 1.34 & - & 0.0 & 91.8 & - & 0.0 \\
EPG-0.10 & 1.36 & - & 0.0 & 92.1 & - & 0.0 \\
EPG-0.20 & 1.29 & - & 0.0 & 89.2 & - & 0.0 \\
EPG-0.30 & 1.34 & - & 0.0 & 89.3 & - & 0.0 \\
EPG-0.40 & 1.28 & - & 0.0 & 85.3 & - & 0.0 \\
EPG-10.0 & 1.45 & 48.2 & 16.5 & 91.6 & 22.7 & 16.5 \\
EPG-10.10 & 1.47 & 49.1 & 17.8 & 92.8 & 22.0 & 16.2 \\
EPG-10.20 & 1.40 & 47.6 & 18.4 & 87.9 & 23.5 & 17.6 \\
EPG-10.30 & 1.39 & 47.8 & 24.2 & 91.1 & 23.2 & 21.4 \\
EPG-20.0 & 1.46 & 50.5 & 36.3 & 88.3 & 21.4 & 34.7 \\
EPG-20.10 & 1.48 & 52.7 & 46.6 & 89.0 & 19.7 & 41.8 \\
EPG-20.20 & 1.45 & 50.4 & 44.5 & 89.4 & 21.2 & 42.1 \\
EPG-30.0 & 1.47 & 51.2 & 55.6 & 89.1 & 20.8 & 56.5 \\
EPG-30.10 & 1.53 & 52.0 & 60.4 & 85.9 & 19.7 & 58.5 \\
EPG-40.0 & 1.53 & 53.0 & 67.6 & 89.3 & 19.3 & 69.7 \\
PCM & 1.86 & 45.9 & 218.1 & - & 27.9 & 217.0 \\
\hline
\end{tabular}

$\mathrm{C}_{\mathrm{p} 30}=$ specific heat at $30^{\circ} \mathrm{C} ; \mathrm{T}_{\mathrm{m} 1}=$ melting temperature of the PCM; $\Delta \mathrm{H}_{\mathrm{m} 1}=$ melting enthalpy of the PCM $\mathrm{T}_{\mathrm{g} 1}=$ glass transition temperature of the epoxy matrix in the first heating scan; $\mathrm{T}_{\mathrm{c}}=$ crystallization temperature of the PCM; $\Delta \mathrm{H}_{\mathrm{C}}=$ crystallization enthalpy of the PCM.

Moreover, the values of $\Delta \mathrm{H}_{\mathrm{m} 1}$ increases with the PCM content and are nearly proportional to the PCM weight fraction. The values of $\Delta \mathrm{H}_{\mathrm{c}}$ are very close to those of $\Delta \mathrm{H}_{\mathrm{m} 1}$, which highlights the reversibility of the process. The melting enthalpy can be also graphically evaluated from Figure 5b, which shows the results of the fitting of the experimental enthalpy data with the linear ternary model (as reported in Section 2.3.4) obtained with a $\mathrm{R}^{2}$ adj value of 0.998 . Some interesting compositions can be EPG-20.20 and EPG-30.20 (the latter can be extrapolated from the model), which capable of storing and releasing approximately $45 \mathrm{~J} / \mathrm{g}$ and $68 \mathrm{~J} / \mathrm{g}$ of thermal energy, respectively.

DSC tests also allowed the determination of $\mathrm{T}_{\mathrm{g} 1}$ and $\mathrm{T}_{\mathrm{g} 2}$ of the epoxy phase and the $c_{p 30}$ of the samples, which are all reported in Table 2. The $T_{g 1}$ of the neat epoxy sample is approximately $92{ }^{\circ} \mathrm{C}$ and does not follow a specific trend with the filler concentration, which confirms that the fillers do not substantially affect the curing process, as shown by rheological tests. However, it is quite difficult to precisely locate the inflection point in DSC thermograms since the signal is less intense at higher filler loadings. The $\mathrm{T}_{\mathrm{g} 1}$ can be better evaluated with DMTA techniques (see Section 3.3). For the values of $\mathrm{c}_{\mathrm{p} 30}$ reported in Table 2, they are mainly affected by the incorporation of PCM. Even though these values have not been measured by following the ASTM E-1269 standard, they are comparable with those found in the literature $[10,48]$ and were thus used to calculate the thermal conductivity.

In order to investigate the TES properties of the prepared samples on a larger scale, a temperature profiling test was carried out during the heating and cooling mode. In this test, cylindric samples with a volume of approximately $10 \mathrm{~cm}^{3}$ were first heated in an oven at $60{ }^{\circ} \mathrm{C}$ and then left cooling at $25^{\circ} \mathrm{C}$ while their inner temperatures were measured with a K-type thermocouple. The results of these tests are reported in Figure $6 \mathrm{a}-\mathrm{d}$. Figure $6 \mathrm{a}, \mathrm{c}$ shows the temperature profiles during the heating and cooling transients, respectively. These profiles clearly highlight the influence of PCM since the samples containing PCM show a plateau-like region at the PCM phase change temperature $\left(43^{\circ} \mathrm{C}\right)$, which is evident especially at higher PCM concentrations. This behavior, already observed in our previous work [20], delays the heating (Figure 6a) and the cooling (Figure 6c) process and increases $t_{26-55}$ and $t_{55-26}$, i.e., the time required for the specimens to reach the surrounding temperature during the heating and cooling transients. For instance, the sample EPG-20.20 takes $19.8 \mathrm{~min}$ to reach $55{ }^{\circ} \mathrm{C}$ in the heating test $(+63 \%$ than neat epoxy), while the sample EPG-40-0 takes $25.6 \mathrm{~min}$ to reach the same temperature $(+111 \%)$. 
These results suggest that the samples with higher PCM loadings are promising for thermal management applications.
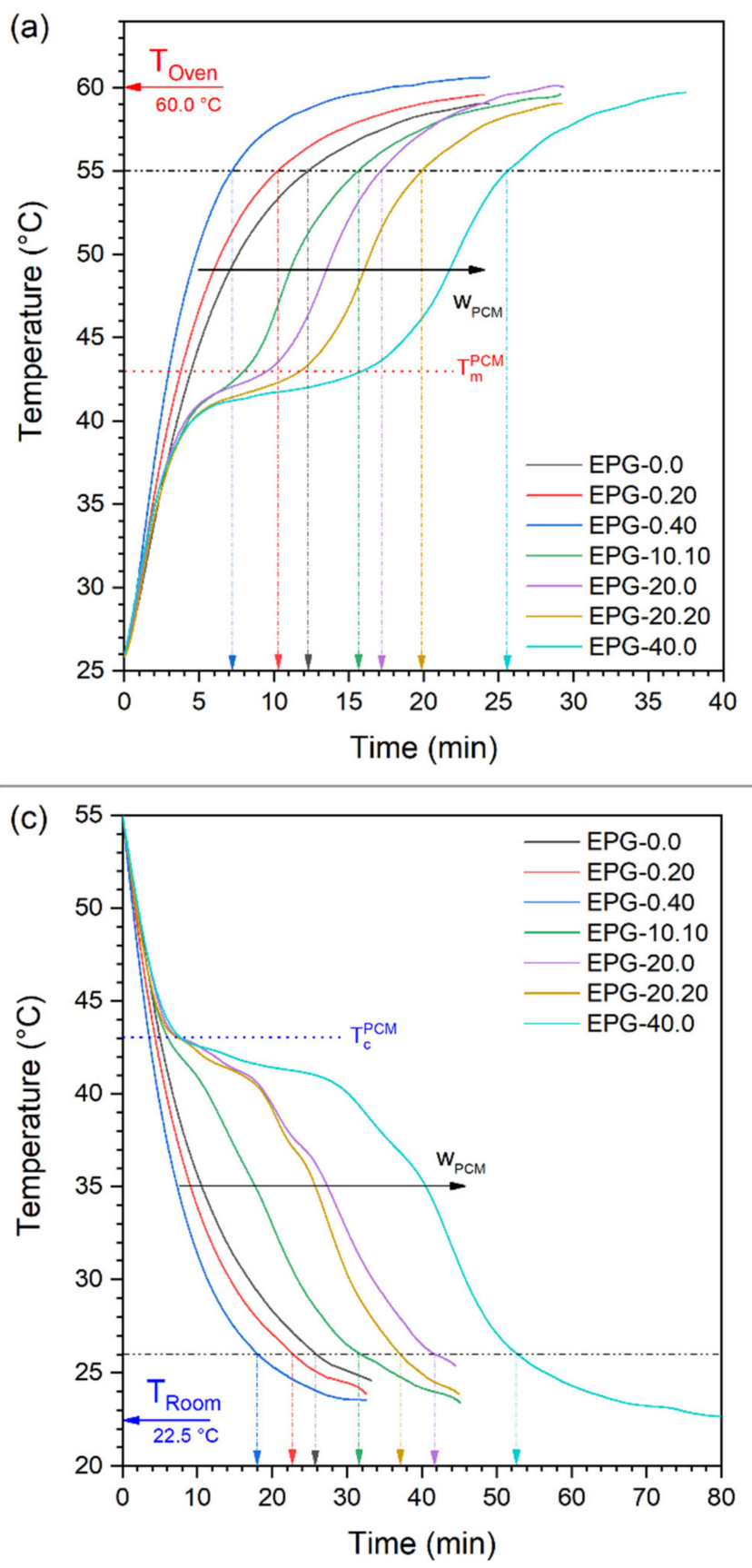

(b)

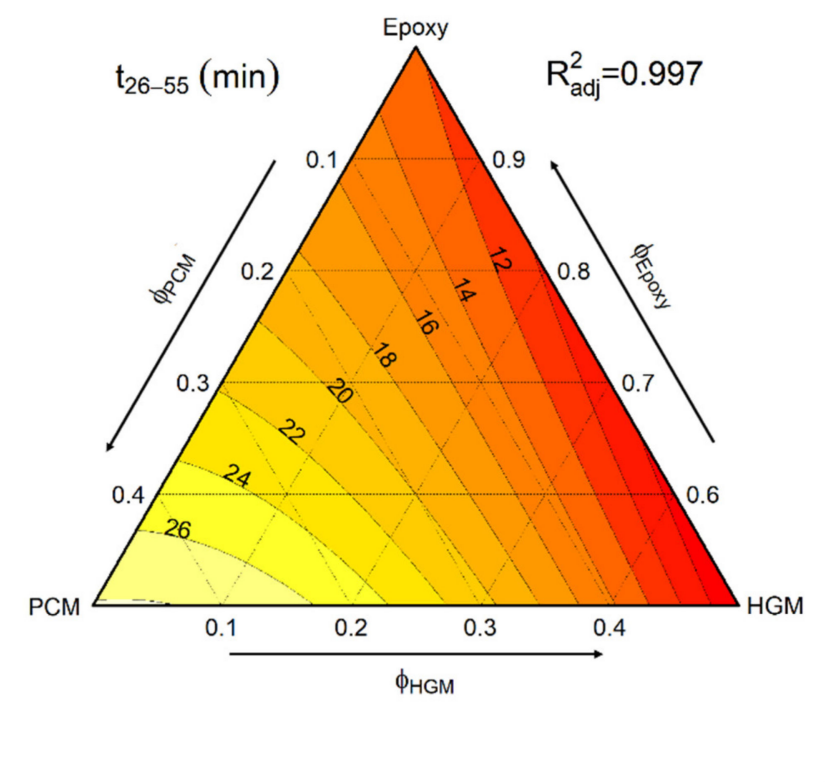

(d)

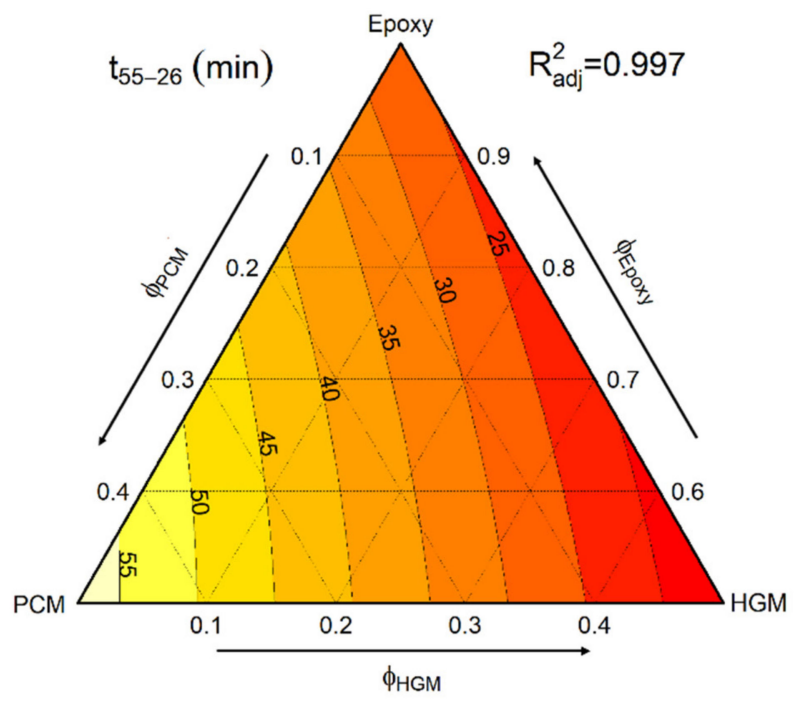

Figure 6. (a) Temperature evolution of the prepared syntactic foams during the heating stage, (b) fit-model of $t_{26-55}$ values, (c) temperature evolution of the prepared syntactic foams during the cooling stage, and (d) fit-model of $t_{55-26}$ values.

The values of $t_{26-55}$ and $t_{55-26}$ were fitted with the linear model $\left(R^{2}\right.$ adj $\left.=0.997\right)$ and the results of the fitting (Figure $6 \mathrm{~b}, \mathrm{~d}$ ) show the effect of the PCM in decreasing the heating and cooling rates. On the other hand, the influence of HGM is unexpected. An increasing HGM content seems to decrease both $t_{26-55}$ and $t_{55-26}$, i.e., to accelerate the heating and cooling processes. The fit-model correctly interprets the experimental data since the temperature profiles of the samples containing only HGM are indeed steeper than that of the neat epoxy. This seems to suggest that HGM favors the thermal exchange, while the opposite is more 
probably true, given their low declared thermal conductivity. These effects can be due to an incorrect positioning of the thermocouple and can therefore be considered part of the experimental error. In fact, this semi-quantitative test was carried out to highlight the TES effects of PCM and not to quantitatively evaluate the thermal conductivity or diffusivity of the samples.

Conversely, a quantitative evaluation of the thermal conductivity and diffusivity of the prepared foams was performed via light flash analysis (LFA), which confirmed the thermal insulation effect of HGM. The instrument returned the values of thermal diffusivity at $30{ }^{\circ} \mathrm{C}$ when used with the value of $\mathrm{c}_{\mathrm{p} 30}$ at $30{ }^{\circ} \mathrm{C}$ (Table 2) and the pycnometer density (Figure 4$)$ to calculate the thermal conductivity $\left(\lambda_{30^{\circ} \mathrm{C}}\right)$ via Equation (2). The values of thermal conductivity were then fitted with a ternary model, resulting in the plot of Figure 7.

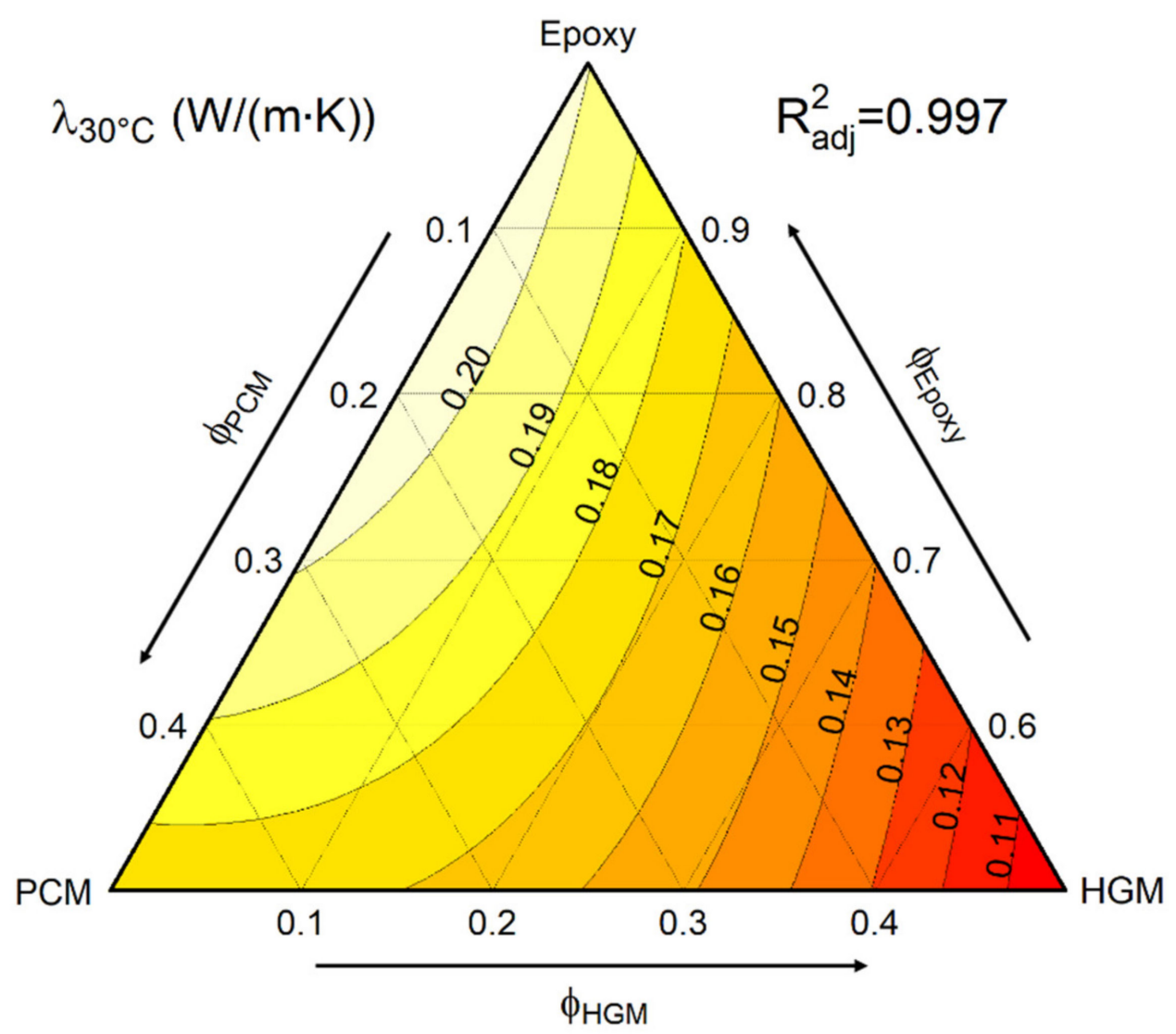

Figure 7. Fit-model of thermal conductivity of the prepared foams at $30{ }^{\circ} \mathrm{C}$.

As expected, an increase in HGM content significantly decreases the thermal conductivity, which is in agreement with the results found in previous literature [49]. On the other hand, the PCM promotes only a modest decrease in thermal conductivity. For example, the value of $\lambda_{30^{\circ} \mathrm{C}}$ for the sample EPG- 40.0 is only $5 \%$ lower than that of neat epoxy, while for EPG-0.40 the reduction in $\lambda_{30^{\circ} \mathrm{C}}$ is close to $40 \%$ (from 0.20 to $0.12 \mathrm{~W} /(\mathrm{m} \cdot \mathrm{K})$ ). Therefore, the optimal composition must be chosen according to the intended application of the foam in order to maximize the TES properties or the thermal insulation capability. Maximizing TES capability could be important when the aim is to manage and smooth temperature peaks of limited duration, while a low value of thermal conductivity could be preferred when the temperature conditions are stationary. Intermediate compositions, such as EPG-20.20 or EPG-30.20, could be a good compromise to match both requirements. 


\subsection{Dynamic-Mechanical Thermal Analysis (DMTA)}

Figure $8 \mathrm{a}, \mathrm{b}$ and Figure $9 \mathrm{a}-\mathrm{c}$ summarizes DMTA results. Figure $8 \mathrm{a}, \mathrm{b}$ demonstrates the trend of the storage modulus $\left(\mathrm{E}^{\prime}\right)$ and the loss tangent $(\tan \delta)$ of the prepared foams as a function of temperature. For neat epoxy, $\mathrm{E}^{\prime}$ decreases with temperature in the entire investigated temperature range but the decrease is faster at approximately $90-100{ }^{\circ} \mathrm{C}$ as the sample undergoes glass transition. This decreasing step in $\mathrm{E}^{\prime}$ is paralleled by a peak in $\tan \delta$. The introduction of HGM does not substantially modify the DMTA behavior of the epoxy matrix since the samples EPG-0.30 and EPG-0.40 also show a single relaxation event at $90-100{ }^{\circ} \mathrm{C}$. However, the values of $\mathrm{E}^{\prime}$ below the glass transition slightly decreases by increasing the HGM fraction, while the opposite is true when above $70^{\circ} \mathrm{C}$. Moreover, the $\mathrm{E}^{\prime}$ inflection point and $\tan \delta$ peak temperature are slightly shifted to higher temperatures upon HGM addition, which suggests that HGM may restrict the mobility of the polymer chains, thereby delaying the glass transition. HGM also decreases the height of the tan $\delta$ peak. These effects are similar to those reported in the literature for other epoxy/HGM systems $[50,51]$ and it can be concluded that the effect of HGM on the viscoelastic behavior of the epoxy resin is relatively modest.
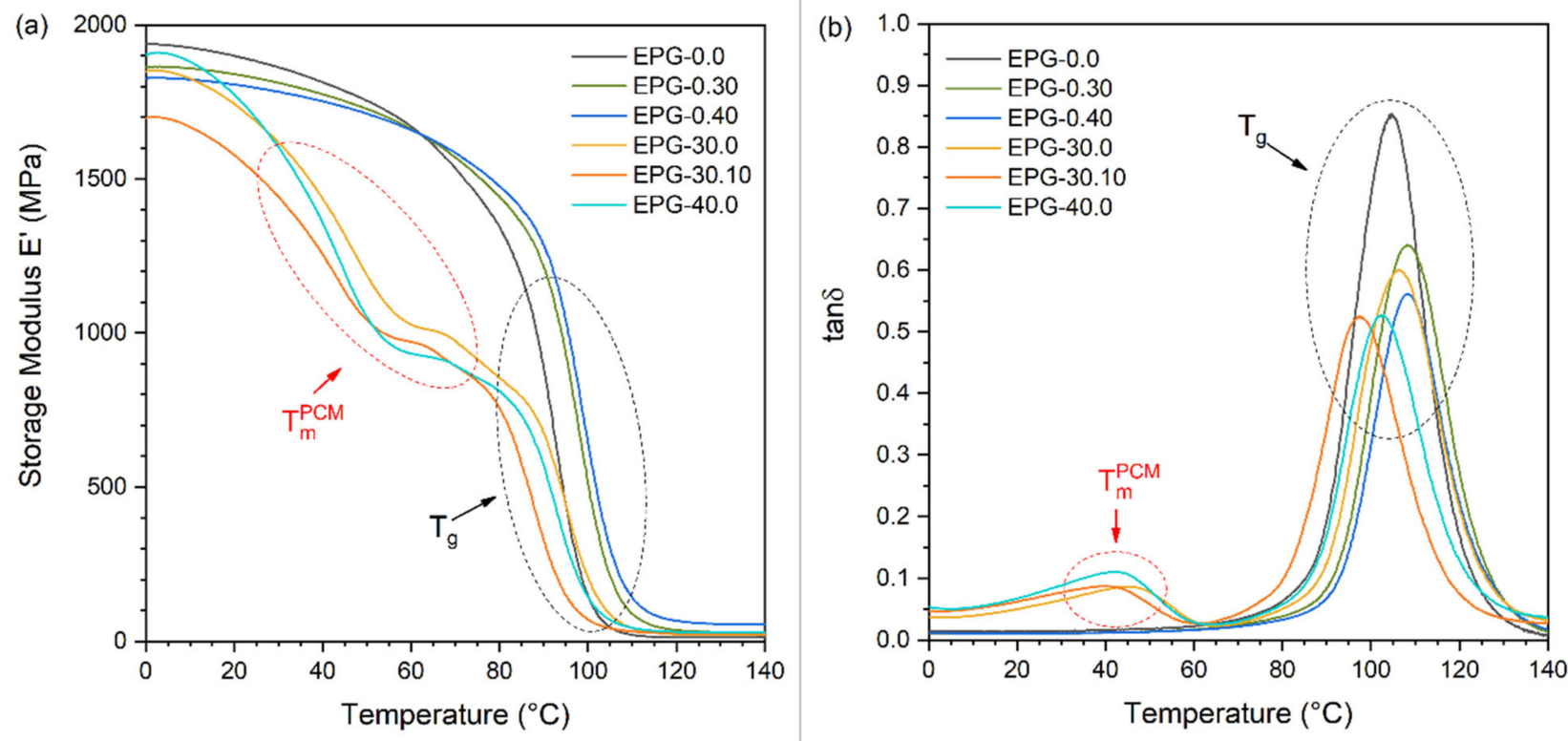

Figure 8. DMTA thermograms of the prepared foams. (a) Storage modulus $E^{\prime}$ and (b) tan $\delta$ as a function of temperature.

What is considerably more evident is the effect played by the PCM. The samples containing PCM show an additional transition in the interval $20-60^{\circ} \mathrm{C}$ with a relative maximum at approximately $40^{\circ} \mathrm{C}$ related to the PCM melting. This transition is highlighted by a marked decrease in $\mathrm{E}^{\prime}$ and a small but evident $\tan \delta$ peak, which is similar to that observed in previous works on composites containing the same PCM [21,38]. Moreover, the $T_{g}$ of the epoxy resin is only slightly influenced by the composition and does not show a clear trend with PCM fraction, which is in agreement with DSC results. This confirms that the PCM and HGM do not interfere with the crosslinking process of epoxy and that the addition of a PCM in a microencapsulated form is suitable to preserve the thermal properties of the resin. In fact, the literature reports some examples in which an epoxy matrix was filled with other types of PCMs, namely shape-stabilized paraffins, and in those cases the PCM domains did influence the mobility of the matrix chains and the value of $\mathrm{T}_{\mathrm{g}}[52,53]$. 

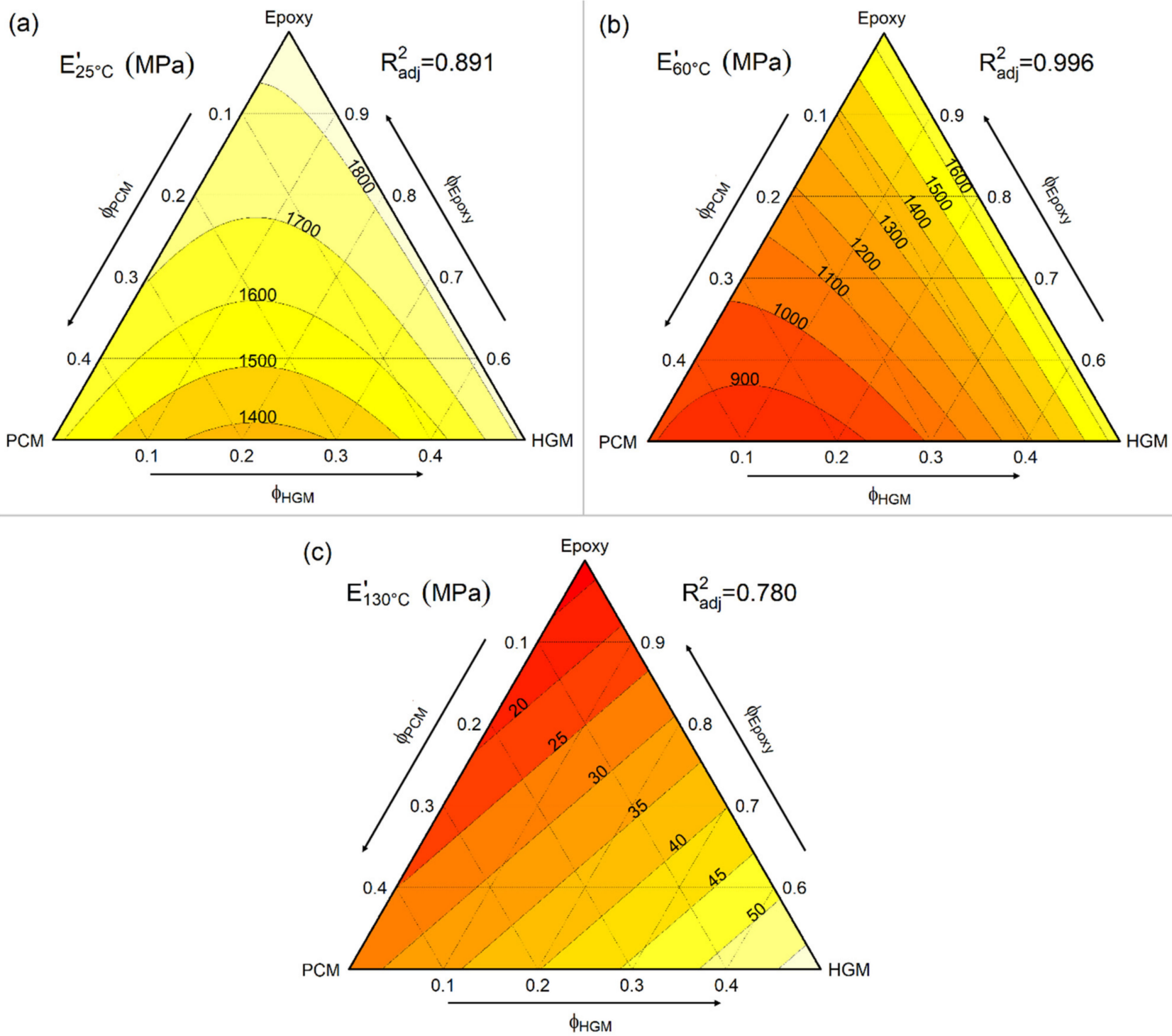

Figure 9. Fit-model of storage modulus $\left(\mathrm{E}^{\prime}\right)$ values at $(\mathbf{a}) 25^{\circ} \mathrm{C},(\mathbf{b})$ at $60^{\circ} \mathrm{C}$, and (c) at $130{ }^{\circ} \mathrm{C}$ from DMTA tests on the prepared syntactic foams.

The effect of PCM and HGM on the values of $\mathrm{E}^{\prime}$ is better illustrated in Figure 9a-c, which shows the fitted models of $\mathrm{E}^{\prime}$ at $25^{\circ} \mathrm{C}, 60^{\circ} \mathrm{C}$, and $130^{\circ} \mathrm{C}$. At $25^{\circ} \mathrm{C}$ (Figure 9a), $\mathrm{E}^{\prime}$ decreases by increasing filler concentration and is more influenced by PCM than by HGM. However, the effect of PCM is considerably more evident at $60{ }^{\circ} \mathrm{C}$ (Figure $9 \mathrm{~b}$ ) between the $\mathrm{T}_{\mathrm{m}}$ of the PCM and the $\mathrm{T}_{\mathrm{g}}$ of the epoxy matrix. Here, $\mathrm{E}^{\prime}$ decreases markedly by increasing the PCM fraction, as the PCM is melted, but it is nearly constant by varying only the HGM content. On the other hand, above the epoxy's $\mathrm{T}_{\mathrm{g}}\left(130^{\circ} \mathrm{C}\right.$, Figure $\left.9 \mathrm{c}\right)$, the filler content has an opposite effect on $\mathrm{E}^{\prime}$. In fact, $\mathrm{E}^{\prime}$ increases with the filler content and especially with the HGM concentration since these stiff particles help in retaining some mechanical properties that are also above the $\mathrm{T}_{\mathrm{g}}$ of the matrix.

Although both PCM and HGM generally decreases the value of $E^{\prime}$, it is important to assess whether this decrease is only due to a decrease in density. In fact, parameters such as the stiffness and strength normalized by density give a more accurate evaluation of the structural performance of the materials than absolute stiffness and strength; thus, they are more often employed for structural design [54]. The resulting specific storage moduli $\left(E^{\prime} / \rho\right)$ (Table 3) evidences the positive contribution of HGM at all the investigated temperatures and this effect increases with temperature. For instance, the sample EPG-0.40 shows an 
$\mathrm{E}^{\prime} / \rho$ value of $2444 \mathrm{MPa} /\left(\mathrm{g} / \mathrm{cm}^{3}\right)$ at $25^{\circ} \mathrm{C}(+48 \%$ than neat epoxy $)$, of $2256 \mathrm{MPa} /\left(\mathrm{g} / \mathrm{cm}^{3}\right)$ at $60{ }^{\circ} \mathrm{C}(+54 \%)$, and of $77 \mathrm{MPa} /\left(\mathrm{g} / \mathrm{cm}^{3}\right)$ at $130{ }^{\circ} \mathrm{C}(+600 \%)$.

Table 3. Selected DMTA data and specific storage modulus $\mathrm{E}^{\prime} / \rho$ at different temperatures of the prepared foams.

\begin{tabular}{lccccc}
\hline Sample & $\begin{array}{c}\mathbf{E}^{\prime \prime} \text { Peak } \\
{ }^{\circ} \mathbf{C} / \mathbf{M P a}\end{array}$ & $\begin{array}{c}\text { tan } \delta \text { Peak } \\
{ }^{\circ} \mathbf{C} /-\end{array}$ & $\begin{array}{c}\mathbf{E}^{\prime} / \rho \\
\mathbf{M P a} /\left(\mathbf{g} / \mathbf{c m}^{3}\right) \\
\mathbf{T}=\mathbf{2 5}{ }^{\circ} \mathbf{C}\end{array}$ & $\begin{array}{c}\mathbf{E}^{\prime} / \rho \\
\mathbf{M P a} /\left(\mathbf{g} / \mathbf{c m}^{3}\right) \\
\mathbf{T}=\mathbf{6 0}{ }^{\circ} \mathbf{C}\end{array}$ & $\begin{array}{c}\mathbf{E}^{\prime} / \boldsymbol{\rho} \\
\mathbf{M P a} /\left(\mathbf{g} / \mathbf{c m}^{3}\right) \\
\mathbf{T}=\mathbf{1 3 0}{ }^{\circ} \mathbf{C}\end{array}$ \\
\hline EPG-0.0 & $94 / 201$ & $105 / 0.85$ & 1655 & 1469 & 11 \\
EPG-0.10 & $98 / 198$ & $106 / 0.63$ & 1646 & 1499 & 24 \\
EPG-0.30 & $99 / 207$ & $108 / 0.64$ & 2073 & 1886 & 34 \\
EPG-0.40 & $100 / 204$ & $108 / 0.56$ & 2444 & 2256 & 77 \\
EPG-10.30 & $99 / 160$ & $107 / 0.57$ & 1982 & 1551 & 51 \\
EPG-30.0 & $96 / 124$ & $107 / 0.60$ & 1642 & 100 & 20 \\
EPG-30.10 & $88 / 118$ & $98 / 0.52$ & 1618 & 1035 & 28 \\
EPG-40.0 & $94 / 114$ & $102 / 0.53$ & 1680 & 925 & 29 \\
\hline
\end{tabular}

The contribution of the PCM is even more temperature-dependent. In fact, at $25^{\circ} \mathrm{C}$ the PCM slightly increases the value of $\mathrm{E}^{\prime} / \rho$ since the sample EPG- 40.0 shows an $\mathrm{E}^{\prime} / \rho$ of $1680 \mathrm{MPa} /\left(\mathrm{g} / \mathrm{cm}^{3}\right)(+1.5 \%$ than neat epoxy). On the other hand, PCM strongly decreases $\mathrm{E}^{\prime} / \rho$ at $60{ }^{\circ} \mathrm{C}$ since the paraffinic core is completely melted but the epoxy matrix is still in the glassy state. For example, the $\mathrm{E}^{\prime} / \rho$ value of EPG- 40.0 foam is $925 \mathrm{MPa} /\left(\mathrm{g} / \mathrm{cm}^{3}\right)$ ( $-37 \%$ than neat epoxy). Finally, at $130{ }^{\circ} \mathrm{C}$ the PCM increases $\mathrm{E}^{\prime} / \rho$ up to $29 \mathrm{MPa} /\left(\mathrm{g} / \mathrm{cm}^{3}\right)$ for the sample EPG-40.0 ( $+163 \%$ than neat epoxy).

In conclusion, even though none of the fillers raise $E^{\prime}$, the reduction in density given by the combination of PCM and HGM leads to a significant increase in $E^{\prime} / \rho$, especially at elevated temperatures. Such materials could therefore be applied as lightweight materials with good specific stiffness in various structural applications.

The results presented so far highlight that the thermal and mechanical properties of these ternary syntactic foams strongly depend on the relative amount of HGM and PCM. In order to select the most suitable composition that optimally combines low density, high mechanical properties, and TES capability a parameter $\mathrm{M}$ representing the multifunctional efficiency was calculated as reported in Equation (4):

$$
\mathrm{M}=\Delta \mathrm{H}_{\mathrm{n}}+\mathrm{E} / \mathrm{n}+v_{\mathrm{n}}
$$

where $\Delta \mathrm{H}_{\mathrm{n}}, \mathrm{E}_{\mathrm{n}}^{\prime}$, and $v_{\mathrm{n}}$ are the normalized enthalpy, the normalized $\mathrm{E}^{\prime}$, and the normalized specific volume, respectively. These three parameters have been calculated by Equations (5)-(7):

$$
\begin{gathered}
\Delta \mathrm{H}_{\mathrm{n}}=\Delta \mathrm{H}_{\mathrm{m} 1} / \max \left(\Delta \mathrm{H}_{\mathrm{m} 1}\right) \\
\mathrm{E}^{\prime} \mathrm{n}=\mathrm{E} / / \max (\mathrm{E} /) \\
v_{\mathrm{n}}=\frac{\frac{v}{\min (v)}-1}{\max \left(\frac{v}{\min (v)}-1\right)}
\end{gathered}
$$

where $\mathrm{E}^{\prime}$ was extracted from the ternary plots at $25^{\circ} \mathrm{C}$ and $60{ }^{\circ} \mathrm{C}$ (Figure $9 \mathrm{a}, \mathrm{b}$ ) and $v$ is the specific volume $1 / \rho$. By using the ternary plots, the $\mathrm{M}$ values of some untested compositions were calculated and reported. The results shown in Figure 10a,b evidences that the compositions EPG-20.20, EPG-20.30, and EPG 30.20 exhibited the highest value of M and therefore are the best combination of properties and the optimal compromise between TES performance, lightness, and stiffness. Moreover, by choosing the right combination of constituents, one can optimize just one of these parameters $\left(\Delta \mathrm{H}_{\mathrm{m}}, \mathrm{E}^{\prime}\right.$, or $\left.\rho\right)$ according to the application requirements. 
(a)

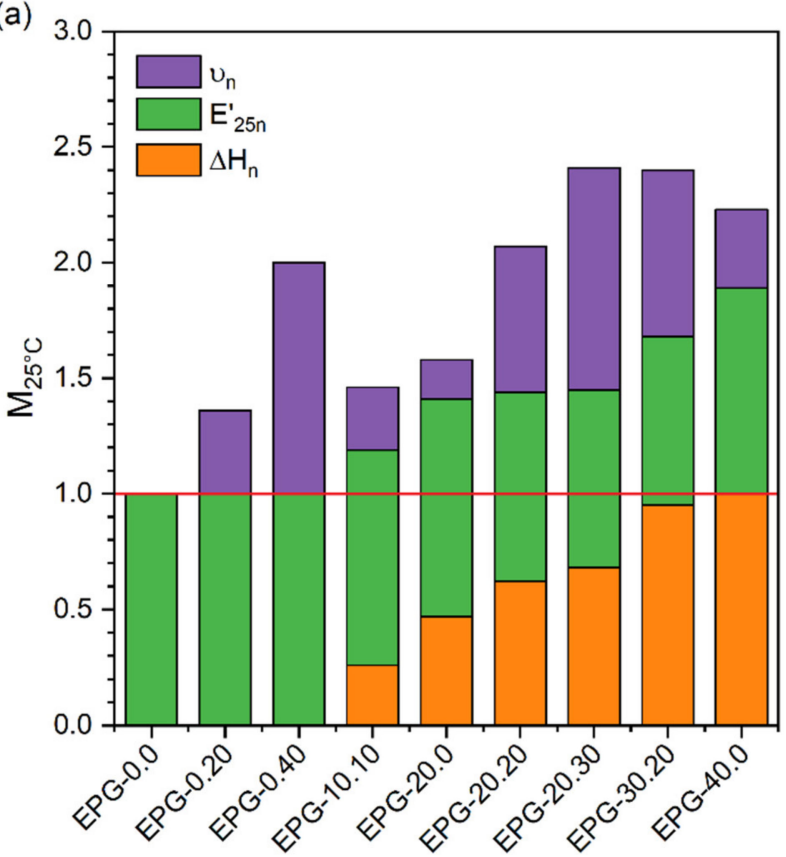

(b)

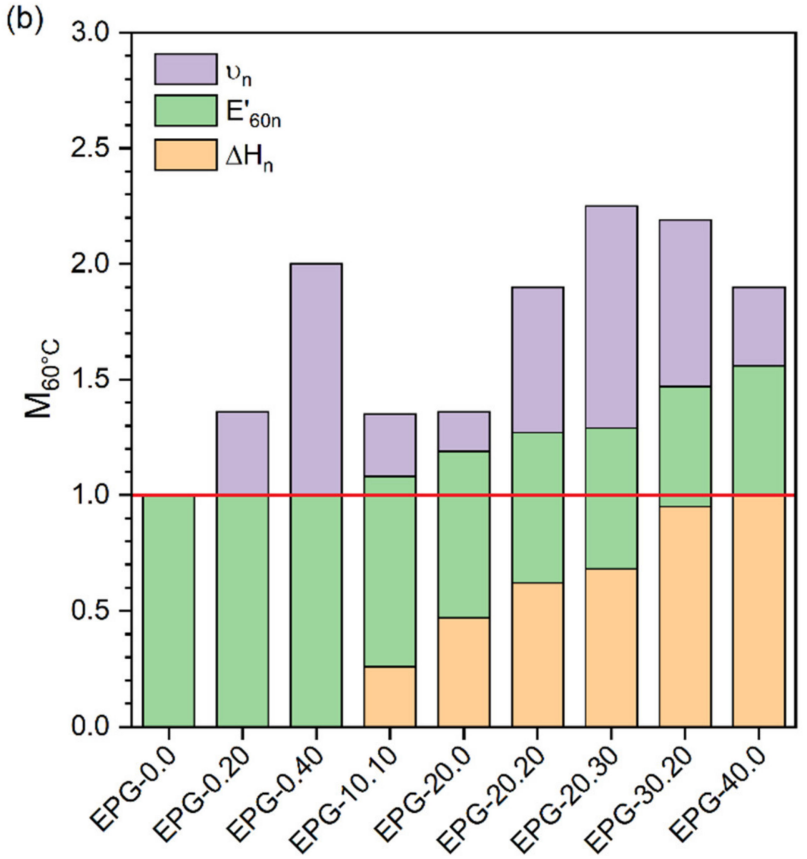

Figure 10. Bar charts representing the multifunctional factor $\mathrm{M}$ at $(\mathrm{a}) 25^{\circ} \mathrm{C}\left(\mathrm{M}_{25^{\circ}} \mathrm{C}\right)$ and $(\mathbf{b}) 60^{\circ} \mathrm{C}\left(\mathrm{M}_{60^{\circ}} \mathrm{C}\right)$.

\section{Conclusions}

In this paper, the incorporation of a microencapsulated PCM into epoxy/HGM syntactic foams resulted in novel multifunctional materials combining low density and thermal management ability. Dynamic rheological tests showed that both PCM and HGM considerably increased the viscosity of the uncured mixtures at elevated filler amounts (up to $+630 \%$ for EPG -40.0 at $\dot{\gamma}=0.2 \mathrm{~s}^{-1}$ ) and the effect of PCM was more marked than that of HGM because of its smaller size $(20 \mu \mathrm{m}$ vs $60 \mu \mathrm{m})$. Moreover, systems containing both PCM and HGM always showed a lower viscosity than foams with a single filler type at the same total filler volume fraction because of the higher maximum packing factors of bimodal filler distributions. Additionally, none of the fillers significantly modified the gel time nor the activation energy of the curing process.

HGM strongly decreased the gravimetric density, which ranged from $1.137 \mathrm{~g} / \mathrm{cm}^{3}$ of neat epoxy down to $0.735 \mathrm{~g} / \mathrm{cm}^{3}$ of the sample EPG-0.40. Furthermore, HGM considerably decreased the thermal diffusivity and conductivity, as is evidenced by LFA, while the PCM decreased the thermal conductivity only marginally. On the other hand, PCM addition determined an increase in the TES properties. In fact, DSC evidenced an increase in melting enthalpy with the PCM content up to $68 \mathrm{~J} / \mathrm{g}$ with a PCM amount of $40 \mathrm{vol} \%$ and temperature profiling tests highlighted interesting thermal management properties in the transient regime.

Finally, DMTA tests showed that $\mathrm{E}^{\prime}$ was generally decreased by both HGM and PCM additions below the $T_{g}$ of the epoxy matrix, while above $T_{g}$ the presence of stiff particles (especially HGM) promoted an increase in $\mathrm{E}^{\prime}$ when compared to unfilled epoxy. On the other hand, the values of specific storage modulus $\left(E^{\prime} / \rho\right)$ increased with the HGM concentration and this was more evident at higher temperatures. The PCM generally decreased $E^{\prime} / \rho$, especially below the $T_{g}$ of the epoxy matrix.

Overall, these results showed that the main asset of these ternary multifunctional systems was their versatility since the property set could be tuned according to the requirements of specific applications. The selection of the best composition could be facilitated by the proposed linear ternary fitting models, which further allowed the evaluating of properties of intermediate compositions between those experimentally investigated in this work. For instance, some compositions showing balanced properties and the highest values 
of the multifunctional parameter M could be EPG-20.20 and EPG-30.20. In fact, EPG-20.20 had a density of $0.872 \mathrm{~g} / \mathrm{cm}^{3}$, a heat storage capacity of $45 \mathrm{~J} / \mathrm{g}$, and a thermal conductivity of $0.17 \mathrm{~W} /(\mathrm{m} \cdot \mathrm{K})$ while EPG-30.20 showed a predicted density of $0.85 \mathrm{~g} / \mathrm{cm}^{3}$, heat storage capacity of $68 \mathrm{~J} / \mathrm{g}$, and thermal conductivity of $0.16-0.17 \mathrm{~W} /(\mathrm{m} \cdot \mathrm{K})$.

The presented results can be considered as a general and useful guide to develop epoxy/HGM syntactic foams containing microencapsulated PCMs, which is promising in applications where highly specific mechanical properties, low thermal conductivity, and thermal management properties are required simultaneously, such as the transportation and refrigeration industries.

Author Contributions: Conceptualization, A.D. and F.G.; methodology, F.G. and A.D; validation, F.G., A.D., and L.F.; formal analysis, F.G.; investigation, F.G.; resources, A.D. and L.F.; data curation, F.G.; writing — original draft preparation, F.G.; writing — review and editing, G.F., A.D., L.F., and A.P.; supervision, A.D. and L.F.; project administration, A.D. All authors have read and agreed to the published version of the manuscript.

Funding: This research received no external funding.

Data Availability Statement: The data presented in this study are available upon request from the corresponding author.

Acknowledgments: Haroon Mahmood is gratefully acknowledged for performing the SEM analysis.

Conflicts of Interest: The authors declare no conflict of interest.

\begin{tabular}{|c|c|c|}
\hline$\alpha$ & thermal diffusivity of the samples at $30^{\circ} \mathrm{C}$ measured by LFA & $\mathrm{mm}^{2} / \mathrm{s}$ \\
\hline$\dot{\gamma}$ & shear rate & $\mathrm{s}^{-1}$ \\
\hline$\Delta \mathbf{H}_{\mathrm{m}}$ & specific enthalpy of fusion & $\mathrm{J} / \mathrm{g}$ \\
\hline$\Delta \mathbf{H}_{\mathrm{c}}$ & specific enthalpy of crystallization & $\mathrm{J} / \mathrm{g}$ \\
\hline$\eta$ & viscosity & $\mathrm{Pa} \cdot \mathrm{s}$ \\
\hline$\lambda_{30^{\circ} \mathrm{C}}$ & thermal conductivity at $30^{\circ} \mathrm{C}$ & $\mathrm{W} /(\mathrm{m} \cdot \mathrm{K})$ \\
\hline$v$ & specific volume (i.e., $1 / \rho$ ) & $\mathrm{cm}^{3} / \mathrm{g}$ \\
\hline$\rho$ & pyconmeter density at $23^{\circ} \mathrm{C}$ & $\mathrm{g} / \mathrm{cm}^{3}$ \\
\hline$\phi_{\text {Epoxy }}$ & volume fraction of epoxy & - \\
\hline$\phi_{\mathbf{P C M}}$ & volume fraction of PCM & - \\
\hline$\phi_{\text {HGM }}$ & volume fraction of HGM & - \\
\hline$c_{p}$ & specific heat capacity & $\mathrm{J} /(\mathrm{g} \cdot \mathrm{K})$ \\
\hline $\mathrm{E}^{\prime}$ & storage modulus & $\mathrm{MPa}$ \\
\hline$E^{\prime \prime}$ & loss modulus & $\mathrm{MPa}$ \\
\hline $\mathrm{G}^{\prime}$ & shear storage modulus & $\mathrm{MPa}$ \\
\hline$G^{\prime \prime}$ & shear loss modulus & $\mathrm{MPa}$ \\
\hline M & multifunctional efficiency coefficient & - \\
\hline $\mathbf{t}_{26-55}$ & time for heating from $26^{\circ} \mathrm{C}$ to $55^{\circ} \mathrm{C}$ & $\min$ \\
\hline $\mathbf{t}_{55-26}$ & time for cooling from $55^{\circ} \mathrm{C}$ to $26^{\circ} \mathrm{C}$ & $\min$ \\
\hline $\tan \delta$ & loss tangent (i.e., $\mathrm{E}^{\prime \prime} / \mathrm{E}^{\prime}$ ) & - \\
\hline $\mathrm{T}_{\mathrm{c}}$ & crystallization temperature & ${ }^{\circ} \mathrm{C}$ \\
\hline $\mathrm{T}_{\mathrm{g}}$ & glass transition temperature & ${ }^{\circ} \mathrm{C}$ \\
\hline $\mathrm{T}_{\mathrm{m}}$ & melting temperature & ${ }^{\circ} \mathrm{C}$ \\
\hline
\end{tabular}

\section{References}

1. Wu, X.; Gao, Y.; Wang, Y.; Fan, R.; Ali, Z.; Yu, J.; Yang, K.; Sun, K.; Li, X.; Lei, Y.; et al. Recent developments on epoxy-based syntactic foams for deep sea exploration. J. Mater. Sci. 2021, 56, 2037-2076. [CrossRef]

2. Qi, C.; Yu, Q.; Zhao, Y. Fabrication and characterization of the thermoplastic and thermoset syntactic foam cor-based sandwich composites. Polym. Compos. 2020, 41, 3052-3061. [CrossRef]

3. Ya, B.; Wang, Y.; Meng, L.; Zhou, B.; Zhang, X. Study on the performance of syntactic foam reinforced by hybrid functionalized carbon nanotubes. J. Appl. Polym. Sci. 2020, 137, 1-8. [CrossRef] 
4. Gupta, N.; Zeltmann, S.E.; Shunmugasamy, V.C.; Pinisetty, D. Applications of Polymer Matrix Syntactic Foams. JOM 2014, 66, 245-254. [CrossRef]

5. Doddamani, M. Effect of surface treatment on quasi-static compression and dynamic mechanical analysis of syntactic foams. Compos. Part B: Eng. 2019, 165, 365-378. [CrossRef]

6. Davarpanah, A. A feasible visual investigation for associative foam polymer injectivity performances in the oil recovery enhancement. Eur. Polym. J. 2018, 105, 405-411. [CrossRef]

7. Davarpanah, A.; Shirmohammadi, R.; Mirshekari, B. Experimental evaluation of polymer-enhanced foam transportation on the foam stabilization in the porous media. Int. J. Environ. Sci. Technol. 2019, 16, 8107-8116. [CrossRef]

8. Afolabi, L.O.; Ariff, Z.M.; Hashim, S.F.S.; Alomayri, T.; Mahzan, S.; Kamarudin, K.-A.; Muhammad, I.D. Syntactic foams formulations, production techniques, and industry applications: A review. J. Mater. Res. Technol. 2020, 9, 10698-10718. [CrossRef]

9. Waddar, S.; Pitchaimani, J.; Doddamani, M.; Gupta, N. Buckling and Free Vibration Behavior of Cenosphere/Epoxy Syntactic Foams under Axial Compressive Loading. Mater. Perform. Charact. 2018, 7, 532-546. [CrossRef]

10. Robert, T.M.; Nair, S.; Mathew, D.; Nair, C.R. Room temperature processable heat-resistant epoxy-oxazolidone-based syntactic foams. Polym. Adv. Technol. 2018, 29, 121-129. [CrossRef]

11. Paul, D.; Velmurugan, R. Analysis of the specific properties of glass microballoon-epoxy syntactic foams under tensile and flexural loads. Mater. Today Proc. 2018, 5, 16956-16962. [CrossRef]

12. Pinisetty, D.; Shunmugasamy, V.C.; Gupta, N. Hollow Glass Microspheres in Thermosets-Epoxy Syntactic Foams. In Hollow Glass Microspheres for Plastics, Elastomers, and Adhesives Compounds; William Andrew Publishing: Norwich, UK, 2015; pp. 147-174.

13. Ding, J.; Ye, F.; Liu, Q.; Yang, C.; Gao, Y.; Zhang, B. Co-continuous hollow glass microspheres/epoxy resin syntactic foam prepared by vacuum resin transfer molding. J. Reinf. Plast. Compos. 2019, 38, 896-909. [CrossRef]

14. Ozkutlu, M.; Dilek, C.; Bayram, G. Effects of hollow glass microsphere density and surface modification on the mechanical and thermal properties of poly(methyl methacrylate) syntactic foams. Compos. Struct. 2018, 202, 545-550. [CrossRef]

15. Gupta, N.; Pinisetty, D. A Review of Thermal Conductivity of Polymer Matrix Syntactic Foams-Effect of Hollow Particle Wall Thickness and Volume Fraction. JOM 2012, 65, 234-245. [CrossRef]

16. He, S.; Carolan, D.; Fergusson, A.; Taylor, A.C. Toughening epoxy syntactic foams with milled carbon fibres: Mechanical properties and toughening mechanisms. Mater. Des. 2019, 169, 107654. [CrossRef]

17. Composite Materials, Processing, Applications, Characterizations; Kar, K.K. (Ed.) Springer Nature: Basingstoke, UK, 2016.

18. Sivanathan, A.; Dou, Q.; Wang, Y.; Li, Y.; Corker, J.; Zhou, Y.; Fan, M. Phase change materials for building construction: An overview of nano-/micro-encapsulation. Nanotechnol. Rev. 2020, 9, 896-921. [CrossRef]

19. Borreguero, A.M.; Rodríguez, J.F.; Valverde, J.L.; Peijs, T.; Carmona, M. Characterization of rigid polyurethane foams containing microencapsulted phase change materials: Microcapsules type effect. J. Appl. Polym. Sci. 2013, 128, 582-590. [CrossRef]

20. Fredi, G.; Dorigato, A.; Pegoretti, A. Novel reactive thermoplastic resin as a matrix for laminates containing phase change microcapsules. Polym. Compos. 2019, 40, 3711-3724. [CrossRef]

21. Fredi, G.; Dorigato, A.; Pegoretti, A. Dynamic-mechanical response of carbon fiber laminates with a reactive thermoplastic resin containing phase change microcapsules. Mech. Time-Depend. Mater. 2020, 24, 395-418. [CrossRef]

22. El Mays, A.; Ammar, R.; Hawa, M.; Akroush, M.A.; Hachem, F.; Khaled, M.; Ramadan, M. Using phase change material in under floor heating. Energy Procedia 2017, 119, 806-811. [CrossRef]

23. Dorigato, A.; Canclini, P.; Unterberger, S.H.; Pegoretti, A. Phase changing nanocomposites for low temperature thermal energy storage and release. Express Polym. Lett. 2017, 11, 738-752. [CrossRef]

24. Stritih, U.; Tyagi, V.; Stropnik, R.; Paksoy, H.; Haghighat, F.; Joybari, M.M. Integration of passive PCM technologies for net-zero energy buildings. Sustain. Cities Soc. 2018, 41, 286-295. [CrossRef]

25. Anisur, M.; Mahfuz, M.; Kibria, M.; Saidur, R.; Metselaar, I.; Mahlia, T. Curbing global warming with phase change materials for energy storage. Renew. Sustain. Energy Rev. 2013, 18, 23-30. [CrossRef]

26. Michel, B.; Glouannec, P.; Fuentes, A.; Chauvelon, P. Experimental and numerical study of insulation walls containing a composite layer of PU-PCM and dedicated to refrigerated vehicle. Appl. Therm. Eng. 2017, 116, 382-391. [CrossRef]

27. Waqas, A.; Kumar, S. Thermal performance of latent heat storage for free cooling of buildings in a dry and hot climate: An experimental study. Energy Build. 2011, 43, 2621-2630. [CrossRef]

28. Serrano, A.; Borreguero, A.M.; Garrido, I.; Rodríguez, J.F.; Carmona, M. Reducing heat loss through the building envelope by using polyurethane foams containing thermoregulating microcapsules. Appl. Therm. Eng. 2016, 103, 226-232. [CrossRef]

29. Sarı, A.; Alkan, C.; Döğüşcü, D.K.; Biçer, A. Micro/nano-encapsulated n-heptadecane with polystyrene shell for latent heat thermal energy storage. Sol. Energy Mater. Sol. Cells 2014, 126, 42-50. [CrossRef]

30. Yang, C.; Fischer, L.; Maranda, S.; Worlitschek, J. Rigid polyurethane foams incorporated with phase change materials: A state-of-the-art review and future research pathways. Energy Build. 2015, 87, 25-36. [CrossRef]

31. Fredi, G.; Dorigato, A.; Fambri, L.; Unterberger, S.H.; Pegoretti, A. Effect of phase change microcapsules on the thermo-mechanical, fracture and heat storage properties of unidirectional carbon/epoxy laminates. Polym. Test. 2020, 91, 106747. [CrossRef]

32. Fredi, G.; Dorigato, A.; Fambri, L.; Pegoretti, A. Multifunctional epoxy/carbon fiber laminates for thermal energy storage and release. Compos. Sci. Technol. 2018, 158, 101-111. [CrossRef]

33. Fredi, G.; Dorigato, A.; Unterberger, S.; Artuso, N.; Pegoretti, A. Discontinuous carbon fiber/polyamide composites with microencapsulated paraffin for thermal energy storage. J. Appl. Polym. Sci. 2019, 136, 1-14. [CrossRef] 
34. Fredi, G.; Dirè, S.; Callone, E.; Ceccato, R.; Mondadori, F.; Pegoretti, A. Docosane-Organosilica Microcapsules for Structural Composites with Thermal Energy Storage/Release Capability. Materials 2019, 12, 1286. [CrossRef] [PubMed]

35. Dorigato, A.; Fredi, G.; Pegoretti, A. Application of the thermal energy storage concept to novel epoxy-short carbon fiber composites. J. Appl. Polym. Sci. 2019, 136, 1-9. [CrossRef]

36. Fredi, G.; Dorigato, A.; Pegoretti, A. Multifunctional glass fiber/polyamide composites with thermal energy storage/release capability. Express Polym. Lett. 2018, 12, 349-364. [CrossRef]

37. Lawson, J.; Willden, C. Mixture Experiments in R Using mixexp. J. Stat. Softw. 2016, 72, 1-20. [CrossRef]

38. Fredi, G.; Dorigato, A.; Fambri, L.; Pegoretti, A. Detailed experimental and theoretical investigation of the thermomechanical properties of epoxy composites containing paraffin microcapsules for thermal management. Polym. Eng. Sci. 2020, 60, 1202-1220. [CrossRef]

39. Rueda, M.M.; Auscher, M.-C.; Fulchiron, R.; Périé, T.; Martin, G.; Sonntag, P.; Cassagnau, P. Rheology and applications of highly filled polymers: A review of current understanding. Prog. Polym. Sci. 2017, 66, 22-53. [CrossRef]

40. Chang, C.; Powell, R.L. Dynamic simulation of bimodal suspensions of hydrodynamically interacting spherical particles. J. Fluid Mech. 1993, 253, 1-25. [CrossRef]

41. Qi, F.; Tanner, R.I. Random close packing and relative viscosity of multimodal suspensions. Rheol. Acta 2011, 51, 289-302. [CrossRef]

42. Qi, F.; Tanner, R.I. Relative viscosity of bimodal suspensions. Korea-Aust. Rheol. J. 2011, 23, 105-111. [CrossRef]

43. Spangenberg, J.; Scherer, G.W.; Hopkins, A.B.; Torquato, S. Viscosity of bimodal suspensions with hard spherical particles. J. Appl. Phys. 2014, 116, 184902. [CrossRef]

44. Ullas, A.V.; Kumar, D.; Roy, P.K. Epoxy-Glass Microballoon Syntactic Foams: Rheological Optimization of the Processing Window. Adv. Polym. Technol. 2019, 2019, 1-12. [CrossRef]

45. Fredi, G.; Zimmerer, C.; Scheffler, C.; Pegoretti, A. Polydopamine-Coated Paraffin Microcapsules as a Multifunctional Filler Enhancing Thermal and Mechanical Performance of a Flexible Epoxy Resin. J. Compos. Sci. 2020, 4, 174. [CrossRef]

46. Fredi, G.; Simon, F.; Sychev, D.; Melnyk, I.; Janke, A.; Scheffler, C.; Zimmerer, C. Bioinspired Polydopamine Coating as an Adhesion Enhancer Between Paraffin Microcapsules and an Epoxy Matrix. ACS Omega 2020, 5, 19639-19653. [CrossRef] [PubMed]

47. Fredi, G.; Bruenig, H.; Vogel, R.; Scheffler, C. Melt-spun polypropylene filaments containing paraffin microcapsules for multifunctional hybrid yarns and smart thermoregulating thermoplastic composites. Express Polym. Lett. 2019, 13, $1071-1087$. [CrossRef]

48. Devi, K.A.; John, B.; Nair, C.P.R.; Ninan, K.N. Syntactic foam composites of epoxy-allyl phenol-bismaleimide ternary blendProcessing and properties. J. Appl. Polym. Sci. 2007, 105, 3715-3722. [CrossRef]

49. Xing, Z.; Ke, H.; Wang, X.; Zheng, T.; Qiao, Y.; Chen, K.; Zhang, X.; Zhang, L.; Bai, C.; Li, A.Z. Investigation of the Thermal Conductivity of Resin-Based Lightweight Composites Filled with Hollow Glass Microspheres. Polymers 2020, 12, 518. [CrossRef]

50. Zeltmann, S.E.; Chen, B.; Gupta, N. Thermal expansion and dynamic mechanical analysis of epoxy matrix-borosilicate glass hollow particle syntactic foams. J. Cell. Plast. 2017, 54, 463-481. [CrossRef]

51. Imran, M.; Rahaman, A.; Pal, S. Morphology and mechanical characterization of carbon nanotubes/epoxy based material filled with hollow glass microsphere. Mater. Res. Express 2020, 7, 025307. [CrossRef]

52. Lian, Q.; Li, K.; Sayyed, A.A.S.; Cheng, J.; Zhang, J. Study on a reliable epoxy-based phase change material: Facile preparation, tunable properties, and phase/microphase separation behavior. J. Mater. Chem. A 2017, 5, 14562-14574. [CrossRef]

53. Sundararajan, S.; Kumar, A.; Chakraborty, B.C.; Samui, A.B.; Kulkarni, P. Poly(ethylene glycol) (PEG)-modified epoxy phasechange polymer with dual properties of thermal storage and vibration damping. Sustain. Energy Fuels 2018, 2, 688-697. [CrossRef]

54. Ashby, M.F.; Johnson, K. Materials and Design: The Art and Science of Material Selection in Product Design, 3rd ed.; ButterworthHeinemann: Waltham, MA, USA, 2014; ISBN 9780080982052. 